\title{
The Art of Making Everybody Happy: How to Prevent a Secession*
}

\author{
Michel Le Breton ${ }^{\dagger}$ and Shlomo Weber ${ }^{\ddagger}$
}

January 2003

\begin{abstract}
In this paper we examine compensation schemes that prevent a threat of secession by all country's regions. We prove that, under quite general assumptions on the distribution of citizens' preferences, there exist transfer schemes that are secession-proof. Moreover, we show that these compensation schemes entail a degree of partial equalization among the regions: the gap between advantageous regions has to be reduced but it should never be completely eliminated. We demonstrate that in the case of a uniform distribution of the nation citizens', the secession-proof conditions generate the $50 \%$ compensation rule for disadvantageous regions.
\end{abstract}

JEL Classification Numbers:D70, H20, H73

Keywords: Transfer Schemes, Secession, Efficiency, Stability

Author's E-Mail Address: sweber@mail.smu.edu

\footnotetext{
* A previous version of this paper has been written while the second author was visiting the Department of Fiscal Affairs at the IMF. We with to thank Ehtisham Ahmad, Francis Bloch, Youngsub Chun, Jacques Drèze, Michel Goemans, Philippe Jéhiel, Michael Keen, Ozgür Kibris, Luc Leruth, Lionel McKenzie, Jean-Charles Rochet, Karl Shell, Partho Shomme, Martin Skutella, Enrico Spolaore, Yuval Weber, an anonymous referee, and an editor of this journal for their valuable comments and suggestions. We are grateful to seminar participants at CORE, IMF, LSE, Universities of Brussels, Copenhagen, Rochester, Stockholm, Toulouse, and Brown, Georgetown, Kyoto, New York, Peking, and Seoul National Universities, for their remarks. We would also like to thank Nicholas Gaspard and Monica Sarratt for their help in preparing the manuscript.

† Université de Toulouse I, GREMAQ and IDEI, Toulouse, France.

† Department of Economics, Southern Methodist University, Dallas, USA and CORE, Catholique University of Louvainla-Neuve, Belgium.
} 


\section{Introduction}

The world political map has undergone dramatic changes since World War II. The number of independent countries in the world almost tripled over the second half of the last century, rising from a mere 74 in 1946 to 193 today; 45\% of countries which exist today have a population under 5 million people. The abolition of colonial rule in Africa in the 1960 s created twenty-five new countries. The last decade brought the next major wave of border changes, highlighted by the break-ups of the former Soviet Union, Yugoslavia, Czechoslovakia and the reunification of Germany. Quebec's recent secession bid was defeated by a majority of less than one percent. One can also point out to Belgium's process of "defederalization" and Scotland and Wales' path to devolution. Various types of separatist movements are active in Africa (Nigeria, Senegal, Angola, Ivory Cost), Asia (China, India, Indonesia), Europe (Denmark, Spain, France, Italy, Russia, Yugoslavia), whereas conflicts over fiscal redistribution, regional power and autonomy mushroom all over the globe.

The purpose of our paper is to examine distributive policies of the central government that would prevent a threat of secession by any of country's regions. The government's objective is to design a transfer policy that would make possible advantages of secession for every region inferior to benefits of remaining within integrated country. The analysis of advantages and disadvantages of a secession points out to the trade-off between economies of scale in large countries and the costs of heterogeneity in big populations. As Barro (1991) puts it "We can think of a country's optimal size as emerging from a trade-off: A large country can spread the cost of public goods, over many taxpayers, but a large country is also likely to have a diverse population that is difficult for the central government to satisfy." Larger political jurisdictions bring about several benefits: the per capita cost of producing public goods declines with the population size of the country ${ }^{1}$; larger countries rely more heavily on

\footnotetext{
${ }^{1}$ A large population of taxpayers can share the cost of public goods such as roads, a telephone network, defense, civil servants, and education. Alesina and Wacziarg (1998) show that small countries tend to have bigger governments, and bigger government consumption, as a share of GDP.
}

(continued...) 
more efficient taxes ${ }^{2}$ and enjoy economies of scale in the utilization of computer hardware and software systems in their tax collection ${ }^{3}$; the size of a country's potential market is affected by the size of the jurisdiction in a world with barriers to trade $^{4}$; larger countries are better equipped to absorb uninsurable shocks in different regions ${ }^{5}$; influence and security considerations may also matter ${ }^{6}$. On the other hand being small has its advantages, as their relative ethnic, religious, and cultural homogeneity, is positively correlated with a country's institutional efficiency ${ }^{7}$; small countries are usually more open to trade ${ }^{8}$ and better adjust to dealing with technological changes in the world markets; and interest groups and unproductive activities play a lesser role in smaller countries ${ }^{9}$.

Since the focus of our paper is the analysis of secessions, we consider a model with one nation and do not address a more general issue of border redrawing. It might be possible that in some situations a secession would necessitate a border redrawing in several countries, (e.g., the idea of "Greater Albania" consisting of Albania itself, Kosovo and parts of the former Yugoslavian province of Macedonia, creation of the Basque country from the Basque areas in France and Spain, and the formation of Kurdistan from the Kurdish enclaves in Turkey, Iran and Iraq). It is quite obvious that the

Smaller countries also face substantial costs of maintaining their distinctive language and culture. For example, the economic cost of Iceland's language is about $3 \%$ of the country GNP (The Economist (1998)).

${ }^{2}$ See Easterly and Rebello (1993).

${ }^{3}$ See Ter-Minassian (1997).

${ }^{4}$ See Friedman (1977), Casella (1992), Casella and Feinstein (2002).

${ }^{5}$ See Persson and Tabellini (1996a,b).

${ }^{6}$ See Alesina and Spolaore (1996). In many countries a majority of citizens do not particularly value their country's political and military might, but in some other countries, particularly China, France, Russia, India and Pakistan, the citizens do care about their country's standing and influence in the world. As evidence of this phenomenon, Easterly and Rebello (1993) confirm that large countries spend relatively more on their defense.

${ }^{7}$ See Mauro (1995) for an analysis of countries' language and ethnic diversity.

${ }^{8}$ See Alesina, Spolaore and Wacziarg (2000).

${ }^{9}$ See Barro (1998). 
probability of any of those scenarios to turn into reality any time soon is not very high, and, indeed, most of the secessionist movements and tensions are internal to a nation.

In our framework a national policy consists of two components: a choice of public policy that can be interpreted as composition of public expenditure, location of the central government, tax rates, immigration quotas, or any other issue of a national interest, and a citizen-specific cost allocation designed to cover fixed government costs. This model allows us to examine the trade-off between heterogeneity of citizens' preferences and increasing returns to scale in larger country. The heterogeneity of preferences is described by the density function representing a number of citizens of each type, whereas the advantages of size are captured by sharing the fixed government costs among larger number of citizens.

To address the issue of secession we first examine ${ }^{10}$ whether, given heterogeneity of citizens' preference, it is desirable and socially efficient to maintain the unified country. We consider a notion of efficiency of cooperation between different regions of a country that is the case when all regions are better of under a single national government. The efficiency of cooperation does not necessarily imply that the gains from cooperation can be allocated in such a way that no region can ensure all its citizens a higher payoff than guaranteed by the central government. If no such allocation is feasible, some regions may become secession prone. We investigate the existence of cost allocations that do not create secession prone regions. If such an allocation exists, we call it secession-proof and the cooperation would be stable and sustainable. The requirement of stability is, in principle, stronger

\footnotetext{
${ }^{10}$ In our formal analysis, we opt for a cooperative approach to address this issue. The choice of a cooperative versus noncooperative model is rather delicate task that does not obey very stringent rules. If an interaction between agents is governed by precise rules and protocols, it is appropriate to model it as a strategic form game where all potential moves are described very accurately without a room for mistake. Even in this case one incurs the risk of deriving predictions based on a fragile structure of a specific construction. In absence of a priori protocol for negotiations between parties involved, one may abandon a non-cooperative mode in favor of a an alternative cooperative approach based only on a surplus available to each coalition of players. We believe that in the context of secessions and monetary compensations, it is worthwhile to adopt a protocol-free cooperative approach of this paper. However, one has to recognize that constitutional constraints on secessions, like in Canada and France, could be modeled as a normal form game. Thus, a mixture of two approaches could be used for an analysis of the issues discussed in this paper.
} 
than that of efficiency. However, our first result suggests that, under quite general assumptions, high government costs eliminate the gap between efficiency and stability, thus, reconciling these two notions. Then whenever the cooperation is efficient, it is also stable, and the unified country is not threatened by secession threats.

It is important to mention that the way a cost allocation assigned to country's citizens represents a transfer policy of the central government. The crucial element in designing a secession-proof transfer scheme is the degree of equalization between advantageous and disadvantageous regions of the country. Indeed, some equalization is required in order support disadvantageous regions that may be vulnerable to secessionist threats in the absence of equalization transfers. Thus, one of the central government's objectives is to design an equalization scheme that would eliminate or, at least reduce, the horizontal imbalances between the regions and deter their threat of secession. Ter-Minassian (1997) argues for a need for transfers to address this issue: "If local jurisdictions must rely on their own revenue sources, the poorer jurisdictions will have less resources than the richer ones.

Therefore, they will not be able to finance services at the same level as the richer jurisdictions. Should a country accept this differentiation in the quality of services? If not, there is a need for the transfer of resources from rich to poor jurisdictions." Ahmad and Craig (1997) point out that indeed "national governments may wish to ensure that citizens in different regions and localities have access to a certain modicum of publicly provided services." To achieve this goal, horizontal imbalances in fiscal capacity should be addressed by equalization transfers from the center or between regions. Our second result derives a structure of equalization transfers under the requirement of secessionproofness. It establishes the principle of partial equalization, which asserts that:

in order to prevent a threat of secession by disadvantageous regions, they must be subsidized by advantageous regions and

in order to deter a threat of secession by advantageous regions, their required contributions should not be excessive.

We specifically determine a degree of partial equalization generated by secession-proofness, and show that in the case of the uniform distribution of citizens' preferences, the equalization rate is 
exactly $50 \%$. We also demonstrate that, in absence of a redistribution mechanism, no intervention approach may leave disadvantageous areas of the country prone to secession. On the other hand, the Rawlsian transfer scheme that completely equalizes the fiscal capacities of all regions would cause advantageous regions to threaten to secede.

The principle of partial equalization suggests that, though the gap between advantageous and disadvantageous regions must be reduced, it should not be completely eliminated.

Before proceeding with the body of our analysis, let us briefly discuss the relationship of this work to the most closely related literature ${ }^{11}$.

\section{Some Related Literature}

First, we would like to compare our analysis with that of Alesina and Spolaore (1997) (AS henceforth). The only relevant difference between the two definitions of secession-proofness ${ }^{12}$ is the set of policy instruments available to the country or any of its potentially seceding regions: AS consider the equal share of the government cost whereas we allow for the full range of compensation schemes. The AS result reconciles stability and efficiency in the sense that with an efficient number of countries, no region would want to break away. In our single-country set-up this translates into the elimination of a threat of secession in an efficient nation. As an entry-deterring instrument, transfers, therefore, become redundant if the nation and potential seceding regions are limited to the equalshare cost allocations.

The AS result has, however, been derived under the assumption of the uniform density of citizens' preferences. The uniform distribution is a case of a non-polarized society, and the natural question is whether the irrelevance of equalization schemes as a secession-deterring device would hold under an increased degree of polarization of country's citizens. Haimanko, Le Breton and Weber

\footnotetext{
${ }^{11}$ See also reviews by Bolton, Roland and Spolaore (1996) and Young (1998).

${ }^{12}$ Called C-stability in AS.
} 
(2002) provide a negative answer to this question and show that if the degree of polarization of citizens' characteristics is sufficiently high, then, in absence of transfers, an efficient cooperation, in general, is not stable and the efficiency alone does not eliminate a threat of secession by country's regions. This argument strengthens the need for an examination of equalization schemes as a device against possible secessions in countries where the citizens' preferences exhibit a high degree of polarization and heterogeneity.

The heterogeneity of citizens' preferences over the provision of public goods has been studied by Casella (1992), Casella and Feinstein (2002), Feinstein (1992), Perroni and Scharf $(2001)^{13}$, Wei (1991) who (implicitly or explicitly) utilized the Hotelling location model. Cremer, De Kerchove, and Thisse (1985) develop a model that examines the number and location of public facilities. There is also a literature rooted in the Tiebout tradition (Wooders (1978), Guesnerie and Oddou (1981), (1987), Greenberg and Weber (1986), Weber and Zamir (1986)), where the heterogeneity of preferences among individuals and the impossibility of lump sum financing of public good provision lead to the formation of small jurisdictions. These papers focus on the existence and the characterization of stable partitions of the individuals into jurisdictions, where equilibrium and stability notions capture various scenario concerning the mobility of individuals and groups of individuals across jurisdictions and the decision making process about the level of the public good provision. The equilibrium and stability notions used in these papers represent a mix of cooperative and noncooperative concepts. The non-cooperative nature comes through the usage of the concept of Nash equilibrium and its refinements and a partition of individuals into jurisdictions is an equilibrium if no individual would find it beneficial to move to another jurisdiction. The cooperative features are introduced via allowing coalitional considerations where it is assumed that coalitions can enforce specific feasible plans of action if they desire to do so. The mere knowledge of the payoffs of each coalition is sufficient to make predictions on the likely outcome of the game. Our paper follows this

\footnotetext{
${ }^{13}$ They assume that each jurisdiction decides not only upon the location of its government but also on its size.
} 
tradition by recognizing the role of coalitions without providing without constraining the rules of their formation.

Another related group of papers focuses primarily on the heterogeneity in income rather than individuals' preferences. The first contribution to this line of research has been made by Buchanan and Faith (1987) who explore the limits that the threat of secession puts on the tax burden imposed by the majority (which can be rich or poor). This question is the subject of Bolton and Roland (1997), who develop a model of a two-region nation with different gross income distributions. Their main focus is to examine how the threat of secession determines the choice of a purely distributive taxation rate under the assumption that if secession takes place, all gross incomes are deflated by a common factor. They show that fiscal accommodation in the union reduces the likelihood of secession, but by no means prevents the break-up of the nation under all circumstances. In addition, fiscal accommodation may surprisingly lead to higher taxes. As explained in Persson and Tabellini (1999), the identification of the equilibrium secession-proof tax rate is not straightforward due to the fact that individual preferences may fail to be single-peaked. The Bolton and Roland model has been extended to allow for mobility across borders (Olofsgard (1999)) and the introduction of regionspecific shocks (Fidrmuc (1999)).

Federations may also be considered from a contractual perspective. What sort of arrangements or constitution, including secession clauses, should be considered to promote efficiency? Drèze (1993) investigates how assets and liabilities should be appointed at the time of a secession and argues in favor of distributive neutrality. Bolton and Roland (1997) have interesting insights on the determinants of the most preferred arrangement. Persson and Tabellini (1996a,b) examine a risk sharing argument under moral hazard considerations. More recently, Bordignon and Brusco (2001) over an analysis of secessions rules, arguing that the absence of explicit secession rules can be seen as a commitment device to increase the stability of the federation. A comprehensive analysis of constitutional provisions on country formation was provided by Jéhiel and Scotchmer (2001).

Finally, our paper also relates to the huge empirical public finance literature on transfers across regions targeted at reducing their horizontal imbalances. Implicit transfers across regions are often 
generated by taxation systems and the design of public spending programs. Many countries, including Canada, Belgium, Germany, and Switzerland, have also adopted explicit inter-regional transfer rules that are motivated mostly by equity and solidarity considerations. The literature has focused on whether these rules lead to under-equalization or over-equalization. Although equalization is not driven by equity considerations in our paper, it turns out that secession-proof transfer schemes will entail some form of partial equalization.

The paper is organized as follows. In Section 2 we present the model and formally introduce the concepts of efficiency and stability of cooperation. In Section 3 we introduce the conditions that guarantee that an efficient cooperation is also stable, state our Main result and sketch the its proof. In Section 4 we consider the case of a uniform distribution and examine two important benchmark allocations: the no-compensation allocation that imposes an equal tax on all citizens of the country, and the full-equalization Rawlsian allocation that eliminates the gap between "advantageous" and "disadvantageous" citizens. We show that neither of these two allocations is secession-proof. Finally, we demonstrate that the $50 \%$ compensation rule is the unique linear allocation that remains secession-proof for all values of government costs. Section 5 contains Concluding Remarks. The proofs of all lemmas and propositions are relegated to the Appendix.

\section{The Model}

We consider a country whose citizens have preferences over the unidimensional policy space $I$, given by the interval $[0,1]$ with a mass of 1 . Each citizen has symmetric single-peaked preferences over the set I and we identify each citizen with her ideal point. The distribution of all ideal points (and, thus, of all citizens' preferences) is given by a cumulative distribution function $F$, defined over the space $I$. We assume that $F$ has a density function $f$ that is positive and continuous everywhere on the interval $[0,1]$. 
The country chooses a policy in the issue space $I$. In this paper we adopt a spatial interpretation of our model and identify a policy with a location of the government and we do not distinguish between geographical and preference dimensions. The country has to cover the cost of provision of public good $g$, which we will simply call a government cost. We assume that the cost of the government $g$ is fixed, so if a region of the country secedes from $l$, it will have to cover the same cost g. For simplicity, we restrict our analysis of possible secessions to those subsets of I that consist of the union of a finite number of intervals and we will use the term region for such a subset of citizens.

Suppose now that an individual $t$ belongs to the set $S$, which could be either the unified country $(S=I)$ or a seceding region $(S \subseteq N)$, whose government chooses a location $p \in I$, then the disutility or "transportation" cost incurred by the individual $t, d(t, p)$, is determined by the distance between $t$ and the location of the government:

$$
d(t, p)=\alpha|t-p|
$$

where $\alpha$ is a positive cost coefficient. Denote by

$$
D(S)=\min _{p \in I} \int_{s} d(t, p) f(t) d t
$$

the minimal transportation cost of the citizens of $S^{14}$.

Let us introduce the notion of an S-cost allocation that determines the monetary contribution of each individual $t$ towards the cost of government $g$.

Definition 2.1: A measurable function $x$ defined on the set $S$ is called an $S$-cost allocation if it satisfies the budget constraint:

\footnotetext{
${ }^{14}$ Since $S$ consists of a finite number of connected regions, there always exists an optimal location of the government and, therefore, the cost function is well defined. It is useful to note that for every set $S$ the total transportation cost is minimized when the government location chooses its location at the ideal point of its "median citizen", $m(S)$, that satisfies $\int_{\{t \in \mid t \leq m(S)\}} f(t) d t=\int_{\{t \in S \mid t \geq m(S)\}} f(t) d t$. If $S$ is an interval, then its median citizen is uniquely defined. However, if $S$ consists of a several intervals separated from each other, the median of $S$ is not necessarily unique. To avoid ambiguity we then denote by $m(S)$ the leftmost median of $S$.
} 


$$
\int_{s} x(t) f(t) d t=g
$$

Since in our set-up advantages and disadvantages of a possible secession are common knowledge, we allow for lump sum transfers and do not restrict the mechanism for reallocation of gains from cooperation within each region $S$. Thus every $S$ would minimize its total cost given by the sum of government and transportation costs:

$$
g+D(S)
$$

Since the minimization of transportation cost for country $S$ implies the selection of its median as the government location, the cost allocation $x$ would imply that the total disutility of a citizen $t \in S$ would be:

$$
\alpha|t-m(S)|+x(t)
$$

For notational simplicity we assume hereafter that $\alpha$, the marginal rate of substitution between money and the distance to the location of the government is equal to $1^{15}$.

Since the transportation cost incurred by a citizen is represented by the distance between her location and the policy chosen by the country or the region to which she belongs, it again points out to the aforementioned conflict between heterogeneity and increasing returns to size. Indeed, on one hand, a larger country would require a smaller per capita contribution towards government costs $\mathrm{g}$ given by an S-cost allocation $x$. On the other hand, the bigger the country the larger the chance that the government's location could be far away from citizens living on the margin. One would expect that higher government costs would strengthen the cooperation so that increasing returns to size would outweigh secession tendencies created by heterogeneity of citizens' preferences.

To examine this issue formally, we introduce the notions of efficiency and stability of cooperation. Cooperation between the different regions of the country would be efficient if no break-up of the country into smaller parts can provide the total benefit exceeding that generated by the united

\footnotetext{
${ }^{15}$ With an obvious change of the variables the analysis remains unchanged with $g / \alpha$ instead of $g$.
} 
country. As Wittman (1991) puts it: "two nations would join together (separate) if the economies of scale and scope and the synergy produced by their union created greater (smaller) benefits than the cost."

Consider all possible partitions of the interval / into several connected or disconnected intervals. A typical partition $P$ of $/$ would consist of a number of smaller regions $\left\{S_{1}, S_{2}, \ldots, S_{k}\right\}$ where each individual $t \in I$ belongs to one and only one region in $P$. The following definition in the game-theoretic terminology amounts to super-additivity:

Definition 2.2: The cooperation is efficient if for every partition $P=\left(S_{1}, \ldots, S_{K}\right)$ we have

$$
D(I)+g \leq \sum_{k=1}^{k}\left[D\left(S_{k}\right)+g\right] \text {. }
$$

It is useful to point out that if country is broken up into two parts, $S$ and $T$, the efficiency condition implies that

$$
g \geq D(I)-D(S)-D(T)
$$

Let us now turn to stability of cooperation that requires not only positive gains from cooperation, but also a mechanism that will allocate those gains in such a way that no separate region $S$ can generate a higher payoff to all its members than that guaranteed to them by the central government. Given a cost allocation and location of the central government, regions of a country may contemplate the possibility of secession. If a region $S$ can make its members better off than under the central government, then $S$ would be prone to secession:

Definition 2.3: Consider a pair $(p ; x)$, where $p$ is a location of the national government and $x$ is an $/$ cost allocation. We say that the region $S$ is prone to secession (given $(p ; x)$ ) if

$$
\int_{S}(d(t, p)+(t)) f(t) d t>D(S)+g .
$$


If no region is prone to secession, then the pair $(p ; x)$ is called secession-proof. The cooperation is called stable if there exists a secession-proof allocation.

Since throughout the rest of the paper we deal only with cost allocations defined for the entire interval $I$, we shall call an $I$-cost allocation simply a cost allocation.

We now state an important property of secession-proof allocations. It implies that under secession-proof allocation each region is required to make a nonnegative contribution towards the government costs. That is, secession-proofness rules out direct subsidization. The reason is obvious: if region $S$ receives a net transfer via cost allocation, the burden of the government costs will fall on the rest of the country $T=I$ " $S$ that would make region $T$ prone to secession.

Lemma 2.4: Let $x$ be a cost allocation. Suppose that there exists a region $S$ such that $\int_{S} x(t) f(t) d t<0$. Then for any location of the government $p$ the region $T=ハ S$ is prone to secession and therefore the pair $(p, x)$ is not secession-proof.

To complete this section we would like to point out that gains from cooperation will emerge only if the government cost is sufficiently high. If the government cost is low then no cooperation would emerge. That is:

Proposition 2.5: There is a cut-off value of government costs $g_{e}$ such that cooperation is efficient if and only if $g \geq g_{\mathrm{e}}$.

Similarly, if government cost is low there is a little incentive for different regions to stay together in one country. (In the extreme case where $g$ is zero, every cost allocation would be secession prone.) Conversely, if the government cost is prohibitively high, no region would be able to pose a threat of secession. 
Proposition 2.6: There is a cut-off value of government costs $g_{s}$ such that cooperation is stable if and only if $g \geq g_{s}$.

As we mentioned above, stability of cooperation requires not only positive gains from being together but also the ability to distribute these gains without creating secession prone regions. That is, the stability requirement is stronger than the efficiency one:

Proposition 2.7: If cooperation is stable, it is also efficient, i.e., $g_{s} \geq g_{\mathrm{e}}$.

In the next section we derive the conditions under which stability and efficiency yield the same cut-off value, $g_{s}=g_{e}$. This would determine the lower bound on government costs yielding a secession-proof allocation.

\section{The Main Result}

As we have stressed above, the designer of the transfer scheme will have to meet two possibly conflicting objectives. On one hand, it is important to identify the conditions under which the mere existence of gains from cooperation yields the possibility of reallocating these gains without creating regions that are prone to secession. It is also much easier to verify whether cooperation is efficient by simply observing the economies of scale rather than examining threats of secessions by every region. Our main result reconciles the two objectives: we establish that, under some general conditions, the bounds on efficiency and stability are the same.

We use two conditions to obtain our equivalence result. The first is

Symmetry: $f(\cdot)$ is symmetric with respect to the center, i.e., $f(t)=f(1-t)$ for all $t \in I$. 
This assumption is quite standard. It implies that the midpoint point of the country $1 / 2$ is not only its geographical center but is also the median of the distribution of citizens' location. In our analysis of secession-proof allocations, we therefore restrict our attention to the situations where the government is located in the middle of the country. Thus, instead of considering a pair $(p, x)$ in Definition 2.3, we focus only on cost allocation, assuming that the national government is always located at the point $1 / 2$.

To state our second assumption, we need some additional notation. For each $t \in l$ let $L_{t}$ and $R_{t}$ be the sets of citizens to the left and right of the point $t$, respectively, i.e., $L_{t}=[0, t]$ and $R_{t}=[t, 1]$. For the sets $L_{t}$ and $R_{t}$ denote by $l(t)$ and $r(t)$ their respective medians, i.e., $l(t)=m\left(L_{t}\right)$ and $r(t)=m\left(R_{t}\right)$. It is easy to verify that both functions $l$ and $r$ are differentiable and increasing in $t$, with $l(0)=0, l(1)=1 / 2$, $r(0)=1 / 2$ and $r(1)=1$. Moreover, the symmetry of the distribution implies that for every $t \in I$

$$
r(\mathrm{t})+l(1-t)=1
$$

Our second assumption is:

Gradually Escalating Median (GEM): $l^{\prime}(t)<1$ on the interval [0; 1]

This assumption implies that if we increase the length of the interval $L_{t}=[0, t]$ by a small positive number $\delta$, then the median of the interval $L_{t+\delta}=[0, t+\delta]$ increases by the amount less than $\delta$. Obviously, the symmetry of the distribution represented by (2) immediately implies that if $l^{\prime}(t)<1$ then $r^{\prime}(t)<1$. The class of distribution functions satisfying the condition of gradual escalation is quite large. In particular, it includes all log-concave functions ${ }^{16}$, i.e., those for which the logarithm of the cumulative distribution function $F$ is concave on the interval $[0,1]$ :

\footnotetext{
${ }^{16}$ Log-concavity is a special case of a more general concept of $\rho$-concavity studied in Hardy, Littlewood and Polya (1934). The applications of log-concavity are relatively novel to economic and political science theory (see Caplin and Nalebuff (1991) and Weber (1992)). The difference between our set-up and the models discussed in Caplin and Nalebuff (1991) is that they impose log-concavity on density functions whereas we consider log-concavity of the distribution function.
} 
Remark 3.1: If the distribution function is log-concave it satisfies GEM.

The log-concavity assumption is satisfied for a wide range of symmetric distribution functions. For example, all symmetric distribution functions which are concave and have an increasing density on the interval $[0,1 / 2]$ are log-concave. It is important to note however that the assumptions of GEM and log-concavity allow for populations exhibiting higher density on the borders than in the center. For example, the distribution function whose density is given by

$$
\left\{\begin{array}{l}
-t+1.25 \quad \text { if } \quad t \leq \frac{1}{2} \\
t+0.25 \quad \text { if } \quad t \geq \frac{1}{2}
\end{array}\right.
$$

is log-concave (and therefore satisfies GEM). Moreover, the function whose density is

$$
\begin{cases}-1.2 t+1.3 & \text { if } \quad t \leq \frac{1}{2} \\ 1.2 t+0.1 & \text { if } \quad t \geq \frac{1}{2}\end{cases}
$$

is not log-concave but nevertheless satisfies GEM, and, therefore, also belongs to the class of functions covered by our Main Result (see Figure 1).

\section{FIGURE 1 HERE}

In order to formally state our main result, let us turn to a closer examination of secession-proof allocations. Lemma 2.4 implies that every citizen makes a nonnegative contribution towards government costs. Since we assume the symmetry of the citizen's distribution with respect to the median, it is crucial to examine how the contribution of each citizen is correlated with her distance to the location of the government. We have to take into account horizontal imbalances between regions and design an equalization mechanism between advantageous citizens (those close to the center) and disadvantageous ones (those close to the borders). To what extent, if at all, should the more disadvantageous regions be compensated via resulting cost allocation?

For this end, consider the cost allocation $x_{g}(t)$ which is defined as follows: 


$$
x_{g}(t)= \begin{cases}r(t)+\lambda & \text { if } t \leq \frac{1}{2} \\ r(1-t)+\lambda & \text { if } t \geq \frac{1}{2}\end{cases}
$$

where the value of $\lambda$ is chosen to satisfy the country's budget constraint:

$$
\lambda=g-2 \int_{0}^{\frac{1}{2}} r(t) f(t) d t
$$

It is important to note that the assumption of gradually escalating median guarantees that the allocation $x_{g}(t)$ satisfies the principle of partial equalization. Indeed, the cost allocation $x_{g}(t)=r(t)+\lambda$ is increasing, whereas the total cost $|t-1 / 2|+x_{g}(t)=1 / 2-t+r(t)+\lambda$ decreasing on the interval $[0,1 / 2]$. This means that the closer a citizen to the center the larger her contribution towards government costs is, while the total cost is still higher for those close to the borders. Thus, while some equalization takes place, it is not full. It is interesting to note that in the case of uniform distribution the equalization rate is $50 \%$ (see Section 4). Then we have:

The Main Result: The Symmetry and Gradually Escalating Median assumptions imply $g_{e}=g_{s}$. Moreover, if the level of government costs $g$ satisfies $g \geq g_{e}$, then the allocation $x_{g}(t)$ is secessionproof.

To prove this result we consider a level of government costs $g$ which guarantees that cooperation is efficient, i.e., $g \geq g_{\mathrm{e}}$. Then we consider the cost allocation $x_{g}$ and show that it is secession-proof. Thus, the cooperation is stable, yielding $g_{\mathrm{e}} \geq \mathrm{g}_{\mathrm{s}}$. Since by Proposition $2.7, g_{\mathrm{e}} \leq g_{\mathrm{s}}$, it would imply that $g_{e}=g_{s}$

Note that Remark 3.1 yields the following:

Corollary 3.2: Under symmetry and log-concavity we have $g_{e}=g_{s}$. 
Although the complete proof of the main result is relegated to the Appendix, we would like to describe the method of the proof, which has an independent interest.

Let us first indicate the major difficulty with verifying secession-proofness. It stems from the fact that one cannot rule out a possibility of secession prone regions that consist of disconnected intervals. If we were able to restrict our analysis to connected regions only, we could have used the Greenberg and Weber (1986) result, which yields a stable outcome when only, connected or "consecutive" coalitions are considered. Unfortunately, it is not even true that if there is a secession prone disconnected region, that there exists a connected region prone to secession. The assumption of gradually escalating median plays a major role to remove this obstacle and to allow us to consider connected as the only regions potentially prone to secession.

We proceed in two steps. First we show that for the set of secession-proof cost allocations, only a specific class of connected regions may be prone to secession. Then we show that the issue of secession-proofness translates into a variational problem. More specifically, we consider a set $X$ of cost allocations that satisfy:

$(\alpha) x$ is a continuous and nonnegative function on the interval $[0,1]$;

$(\beta) x$ is symmetric: $x(t)=x(1-t)$ for all $t \in[0,1]$;

$(Y) x$ is increasing on the interval $[0,1 / 2]$.

$(\delta) x(t)-\mathrm{t}$ is decreasing in $t$ on the interval $[0,1 / 2]$.

This simply implies that individuals close to the center make larger contributions towards government cost. However, the total burden that includes transportation costs is still heavier for citizens who live close to the borders.

The following lemma, the proof of which heavily relies upon the GEM assumption, plays the central role in our proof:

Lemma 3.3: Let $x \in X$ be a cost allocation which is not secession-proof. Then there exists $t \in[0,1]$ such that either $L_{t}=[0, t]$ or $R_{t}=[t, 1]$ is prone to secession. 
The intuition is as follows. If a cost allocation entailing some degree of partial equalization is prone to secession by a disconnected region, it is also prone to secession by a connected region that contains at least one of the endpoints of the interval $[0,1]$. Then we are left with an easier task technique consists in filling of examining threats of secession only of connected regions.

Lemma 3.3 implies that for any secession-proof allocation $x \in X$ neither $L_{t}$ nor $R_{t}$ are prone for secession for any $t \in I$, or, equivalently, the following two conditions should be satisfied for all $t \in[0$, 1]:

$$
\begin{aligned}
& \int_{L t}\left(x(t)+\left|t-\frac{1}{2}\right|\right) f(t) d t \leq g+D\left(L_{t}\right) \\
& \int_{R t}\left(x(t)+\left|t-\frac{1}{2}\right|\right) f(t) d t \leq g+D\left(R_{t}\right)
\end{aligned}
$$

where, to recall, $D(S)$ denotes the minimum of the aggregated transportation cost of members of $S$. For every $t$ denote by $H(t)$ the aggregated transportation cost of citizens of $L_{t}$ to the location of the government at $1 / 2$, i.e.,

$$
H(t)=\int_{0}^{t}\left|t-\frac{1}{2}\right| f(t) d t .
$$

Using the symmetry of the citizens' distribution and rearranging the above inequalities, we obtain the necessary and sufficient conditions for a cost allocation $x \in X$ to be secession-proof, namely, that the inequalities

$$
D(I)-D\left(R_{t}\right)-H(t) \leq \int_{0}^{t} x(t) f(t) d t \leq g+D\left(L_{t}\right)-H(t)
$$

hold for all $\mathrm{t} \leq 1 / 2$.

The problem is now reduced to a variational problem: find a cost allocation in $X$ to satisfy the integral conditions in (3). The complete details of the solution to this problem are presented in the Appendix. In the next section we illustrate this problem by considering a special case of a uniform distribution that would help to illuminate both difficulties and their resolution in the general case. 


\section{Uniform Distribution}

In this section we consider the density function that is uniform on the interval $l$, i.e. $f(t)=1$ for all $t \in$ $[0,1]$

It is easy to verify that in this case the necessary and sufficient conditions for secession-proofness in (3) turn into:

$$
\frac{t^{2}}{4} \leq \int_{0}^{t} x(s) d s \leq \psi(t)
$$

for all $t \in[0,1 / 2]$, where $\psi(t) \equiv \frac{3 t^{2}-2 t}{4}+g$. This means that in order to obtain a secession-proof cost allocation, one has to find, for a given value of $g$, a function $y$ sandwiched between $\frac{t^{2}}{4}$ and $\psi(t)$, with $y(0)=0, y(1 / 2)=g / 2, y^{\prime}>0$, and $0<y^{\prime \prime}<1$. Therefore, the search for a secession-proof cost allocation amounts to finding an increasing and convex (but not "too convex") function that connects 0 and $A$ and whose graph lies within the shaded area depicted on Figure 2.

\section{FIGURE 2 HERE}

Our first result of this section derives the explicit value of the minimal threshold $g_{s}$ that guarantees efficiency and stability of cooperation:

Proposition 4.1: The efficiency bound $g_{e}$ is equal to $1 / 8$.

Since every secession-proof allocation requires each individual to make a nonnegative contribution, the question is how the cost of the government $g$ is shared among its citizens in the uniform case. Our Main Result yields a secession-proof allocation $x_{g}(t)(g \geq 1 / 8)$, which determines a contribution of a citizen $t$ : 


$$
x_{g}(t)=\left\{\begin{array}{lll}
\frac{t}{2}+g-\frac{1}{8} & \text { if } & t \leq \frac{1}{2} \\
1-\frac{t}{2}+g-\frac{1}{8} & \text { if } & t \geq \frac{1}{2}
\end{array}\right.
$$

The compensation rate generated by this allocation is $50 \%$. This means that for every two citizens $t<t^{\prime}<1 / 2$, the contribution of citizen $t^{\prime}$ towards government costs exceeds that of citizen $t$ by one half of the distance between $t$ and $t$ '. To reinforce the need for a balanced (partial) equalization, we consider two extreme allocations, no-compensation allocation, under which each citizen contributes an equal amount towards government costs (no equalization), and Rawlsian Egalitarian allocation that assigns equal total contributions (including the transportation cost) to every citizen (full equalization), and show that both are not necessarily secession-proof. The intuitive reasons for that in the case of nocompensation allocation a heavy burden (a lack of subsidy) is put on the distant regions that may be then prone to secession. The full compensation mechanism the burden is almost squarely on the shoulders of central regions, which can make them prone to secession. This intuition is supported by our results.

- No-compensation allocation NC. This allocation assigns an equal burden for all citizens.

Thus, for every $t \in I$

$$
N C(t)=g
$$

We have the following proposition:

Proposition 4.2: There exists a level of government costs $g^{*}=0.134>1 / 8$ such that for all $g, 1 / 8 \leq g \leq g^{*}$, the no-compensation allocation NC is not secession-proof.

Note that the left side of inequality (4) is always satisfied for $g \geq 1 / 8$ as $t \leq 1 / 2$. This means that for $t \leq 1 / 2$ no region $R_{t}$ is prone to secession. The reason is that the citizens in the middle of the country spared from equalization transfers to support distant regions would not wish to secede. The secession prone candidates are, therefore, the regions $L_{t}(t<1 / 2)$, that contain border citizens but do not contain the center 
of the country. It is interesting to mention that only relatively large regions, containing more than $33 \%$ of the population, could be prone to secession. Indeed, small regions on the margin are not prone to secession because of a heavy burden of per capita government costs if they wish to go alone.

- Rawlsian Egalitarian allocation RE. This allocation guarantees an equal total cost (including transportation) for all citizens. Thus, $R E(t)+\mid \mathrm{t}-1 / 2) \mid$ is the same for all $t$.

Then $R E(t)+\mid t-1 / 2) \mid=g+1 / 4$, yielding:

$$
R E(t)=\left\{\begin{array}{lll}
t-\frac{1}{4}+g & \text { if } & t \leq \frac{1}{2} \\
-t+\frac{3}{4}+g & \text { if } & t \leq \frac{1}{2}
\end{array}\right.
$$

(Three cost allocations NC,RE and $x_{g}$ are depicted on Figure 3.)

\section{FIGURE 3 HERE}

Hence for the range of government costs $1 / 8 \leq g<1 / 4$; the values of $R E(t)$ are negative for all $t$ satisfying 0 $\leq t<1 / 4-\mathrm{g}$. This implies that for every $t<1 / 4 \mathrm{~g}$, the citizens of the region $L_{t}$ will receive a net subsidy. Lemma 3.4 yields that it would not be acceptable for the rest of the country. Indeed, since the full equalization puts a heavy burden on citizens close to the center. The corresponding regions $R_{t}$ will be prone to secession. This immediately yields the following:

Proposition 4.3: For any level of government costs $g$ such that $1 / 8 \leq g<1 / 4$, the Rawlsian Egalitarian allocation is not secession-proof ${ }^{17}$.

\section{Linear Compensation Schemes}

17 Jacques Drèze pointed out to us that, if the citizens were distributed (uniformly) over the entire real line, rather than the bounded interval $[0,1]$, the full equalization would be the unique secession-proof compensation scheme. Indeed, in this case for any level of government costs the gains from cooperation are maximized for a partition of real line into intervals of equal length. 
We complete this section by a characterization of the set of linear compensation allocations, where the rate of equalization is uniquely determined by a slope of the allocation function. For a given value of government costs $g \geq 1 / 8$, we consider a symmetric linear cost allocation $\widetilde{x}(t)=\alpha t+\beta$ for all $t \in[0,1 / 2]$, and $\tilde{x}(1-t)=\tilde{x}(t)$, where for each $0 \leq \alpha \leq 1$ the value of $\beta$ is chosen to balance the government budget: $\int_{0}^{1} \widetilde{x}(s) d s=g$ Thus, the allocation $\tilde{x}$ is actually determined by the equalization rate $\alpha$. In order to stress this link we denote $\tilde{x}(t)=x_{g}^{\alpha}(t)$.

Now let us turn to examination of secession-proof linear compensation schemes. Not surprisingly, the range of secession-proof equalization rates crucially depends on the value of $g$. If the value of $g$ declines, it increases a likelihood of secession threats and shrinks the range of secession-proof equalization rates. Specifically, for low levels of $g(0.125 \leq g \leq 0.25)$ this range is quite narrow and for $g=0.125$ it consists of only one point, namely, the $50 \%$ equalization rate. Since $1 / 2$ is always a secession-proof rate, it follows that $50 \%$ equalization rule provides the unique rate that is secessionproof for all values of $g$ exceeding 0.125 .

For relatively high levels of $g \geq 0.25$ the secession-proofness has no implication whatsoever on the range of equalization. Indeed, if the government costs rise, a desire to secede would diminish and at certain point, $g=0.25$ it ceases to affect the equalization rates. Formally,

Proposition 4.4: The allocation $x^{\alpha}$ is secession-proof if the equalization rate $\alpha$ satisfies:

$$
\begin{cases}\psi(g) \leq \alpha \leq 4 g & \text { if } g \in[0.125, .025] \\ 0 \leq \alpha \leq 1 & \text { if } g \geq 0.25\end{cases}
$$

where the function $\psi(g)$ is derived in the Appendix. (The shaded area in Figure 4 represents the secession-proof equalization rates for all possible values of $g$.)

FIGURE 4 HERE 


\section{Concluding Remarks}

In this paper we provide an analytical study of interregional fiscal policies in a country with heterogeneous citizens when different regions may pose a threat of secession. We focus our analysis on the study of compensation schemes that would make possible advantages of secession for every region inferior to benefits of remaining within integrated country.

To address the issue of secession we first examine whether, given heterogeneity of citizens' preferences, it is desirable and socially efficient to maintain the unified country. We consider a notion of efficiency in a country when all regions are better off under a single national government. The efficiency does not necessarily imply that the gains from being together in the integrated country can be allocated in such a way that no region can ensure all its citizens a higher payoff than guaranteed by the central government. We investigate the existence of compensation schemes (cost allocations) across the regions that guarantee that no region would like to secede and break up the country. Such scheme is called secession-proof and country is stable.

The first result of the paper is to show that, under quite general conditions on the distribution of citizens' characteristics, efficiency and stability can be reconciled. That is, if a country is efficient, there is always a secession-proof compensation scheme that guarantees the country stability. We then examine secession-proof transfer schemes and the degree of equalization between advantageous and disadvantageous regions these schemes entail. We establish the principle of partial equalization that the gap between advantageous and disadvantageous regions should be reduced, but it should not be completely eliminated. We determine a degree of partial equalization generated by secession-proofness, and show that in the case of the uniform distribution of citizens' preferences, the equalization rate is exactly $50 \%$. We also demonstrate that, in absence of a redistribution mechanism, some disadvantageous areas of the country could be prone to secession and the no compensation allocation is not secession-proof. On the other hand, the Rawlsian transfer scheme that completely equalizes the fiscal capacities of all regions would cause advantageous regions to threaten to secede. 
The study presented in this paper can be extended in several directions. The focus of this paper was a study of compensation schemes under unanimity procedures and an analysis of alternative mechanisms, such as majority voting, would be a worthwhile contribution. One could also consider a multidimensional policy where the citizens are distinguished by more than one parameter, say, income, geography, and ethnicity. This extension poses a difficult theoretical challenge but its resolution would be very promising both from theoretical and empirical point of view. Finally, one may have a careful look at the issue of migration, in particularly, given heterogeneous tax burden and living conditions across the regions. All those extensions, as well as some other interesting related issues, are left to future research.

We conclude this section by a brief examination of some empirical evidence and review of partial equalization in the real world. In general, the principle of partial equalization prevails in many countries, especially developed ones and, in fact, Australia, Canada, Denmark, Germany, among the others, use horizontal imbalances as the basis of equalization policy between the regions.

Canada. The principle of equalization is a part of the Canadian Constitution and receives a broad national support. There is a variety of transfer programs that attempt to reduce regional inequalities based on capacity, population and needs (Krelove, Stotsky and Vehorn (1997)). The equalization payments were redistributed only to seven relatively poor provinces (in terms of 1990-91 data) while Alberta, British Columbia and Ontario received no payments from this fund (see Table 1).

\section{TABLE 1 HERE}

Clark (1997) points out the success of equalization efforts in reducing regional inequalities. For example, in 1994-95, Alberta's fiscal capacity index before equalization was almost twice as high as that of Newfoundland. However, the equalization entitlement reduced this gap by almost $75 \%$.

Australia. Here, substantial funds are relocated away from the larger states of New South Wales and Victoria to whereas Southern Australia, Tasmania and the Northern Territory serve as major recipients (Craig (1997)). (See Table 2).

TABLE 2 HERE 
Germany. It is interesting to point out that, due to the heavy economic burden of unification of the West and East Germany, the transfer scheme used there exhibited a degree over-equalization. Spahn and Föttinger (1997) (Table 3) show that the fiscal capacity of poorer former East German provinces increased after the transfer, but the contribution paid by rich former West German states reduced their fiscal capacity below the average.

\section{TABLE 3 HERE}

Even though at the first glance it seems incompatible with our model, where a threat of secession (or integration as in the German case) rules out a possibility of over-equalization. One has to recall, however, that the decision on the German re-unification has been made in a manner dictated by the political circumstances of that particular period. Were the public debate in Germany on consequences of reunification, including its enormous cost, to be followed by national elections or referendum, the final decision might been quite different.

The European Union. In their recent paper, Hayo and Wrede (2002) examined an issue of partial equalization in the European Union. Their conclusion was that over the 1986- 1997 period the EU equalization scheme did, in general, conform to the principle of partial equalization. Thus, the stability of the Union could be linked to proper equalization arrangements. Hayo and Wrede have mentioned however that the weakness of the system was its lack of adjustment to change. A major difficulty is to reverse a country status from recipient to donor, which may pose a formidable challenge to stability of the EU after the proposed enlargement in 2004.

In some instances, mainly in developing countries, there is still a chasm between policy intentions and the implementation of compensation mechanisms.

Russia. Triesman $(1996,1998)$ argues that direct financial transfers from the federal budget to the regions in Russia in 1992-1994 were a function of the lobbying power of the regions and the issues of horizontal imbalances were not properly addressed in that period. Indeed, Dabla-Norris, E., MartinezVasquez, J. and J. Norregaard (2000) and Dabla-Norris and Weber (2001) demonstrated that the 
principle of partial equalization was not implemented in Russia over the first part of the last decade and, in fact, the gap between rich and poor Russian regions has even been widened. The best-off region (Moscow) in 1993 spent close to 12 times more in capital expenditures than the worst-off regions with the gap widening to more than 24 times in 1998 (see Table 4).

TABLE 4 HERE

China. Hu and Tan (1996) have demonstrated that, due to governmental policies, the gap between rich and poor provinces in China has declined in 1980s. One of the tools cited in this regard is the "Antimega city" policy that has been initiated in 1986. It was aimed to achieving a certain equalization across the country by placing restrictions on the largest cities of Shanghai, Beijing and Tianjin. Ahmad, Li, Richardson and Singh (2002) argue, however, that "the overall transfer system [in China] continues to be sharply regressive, rewarding wealthy regions with increased transfers." (See Table 5.)

\section{TABLE 5 HERE}

In fact, Hu and Fujita (2001) show that regional disparity between the coastal and interior provinces in China has increased since the mid 1980s and even accelerated after 1990. (For example, the per capita income in Shanghai is ten times larger than in the province of Guizhou). Both Ahmad et al (2002) and Hu and Fujita (2001) consider the increasing gap between rich and poor regions as a serious problem that needs to be addressed at the national level.

It is important to point out that the central governments often use transfer schemes as an appeasement policy towards "target" regions. We have already mentioned the transfer policy of the Russian Federation in early nineties when "trouble-making" regions received a disproportionably large share of the total transfer budget. In China, Tibet receives a large 21 amount of subsidies from the central government and its regional GDP growth has reached almost 12\% over the period 1993-1999, thus, surpassing the national average for the six consecutive years (People's Daily, 2000). One can also mention special privileges granted to the Basque Country in Spain. The Basque Country is allowed to collect its own income tax, corporate tax and VAT, as well as petrol, tobacco and spirits taxes. Then a previously agree quota is transferred to the Spanish treasury as a compensation for Spanish common 
expenditure and the cost of running those state bodies. Thus, the per capita level of public expenditure in the Basque Country is much higher than in the rest of Spain. In fact, is $80 \%$ higher than the level of the public spending in Catalonia and Galicia (Moreno (2001)).

\section{Appendix}

Proof of Lemma 2.4: Let a cost allocation $x$ and a region $S$ be such that $\int_{S} x(t) f(t) d t<0$. Consider the region $T=I \backslash S$ which represents all the individuals outside of $S$. It will have to contribute more than $g$ towards government costs, i.e., $\int_{T} x(t) f(t) d t>g$. Suppose that the government is located at point $p$. The total cost of region $T$ is:

$$
\int_{T}(x(t)+|t-p|) f(t) d t
$$

However, since, $\int_{T} x(t) f(t) d t>g$, and, $\int_{T}|t-p| f(t) d t \geq D(T)$, it follows that

$$
\int_{T}(x(t)+|t-p|) f(t) d t>g+D(T)
$$

and $T$ is prone to secession.

Proof of Proposition 2.5: The cooperation is efficient if for any partition $\left(S_{1}, \ldots, S_{K}\right)$ the following inequality is satisfied:

$$
g+D(I) \leq \sum_{k=1}^{K}\left[g+d\left(S_{k}\right]\right.
$$

Since it is trivially satisfied for $K=1$, we may consider only partitions into $K>1$ regions. Thus, the last inequality can be rewritten as

$$
g \geq \frac{1}{K-1}+\left[D(I)-\sum_{k=1}^{K} D\left(S_{k}\right)\right]
$$

Denote by 


$$
g_{e}=\sup _{P} \frac{1}{|P|-1}\left[D(I)-\sum_{S \in P}^{K} D(S)\right]
$$

where supremum is taken over the set of all partitions $P$ of the nation $/$ into more than one region and $|P|$ stands for the number of regions in $P$. Note that $g_{\mathrm{e}} \leq \mathrm{D}(\mathrm{I}) / 2$ is bounded. Thus, the cooperation is efficient if and only if $g \geq g_{e}$.

Proof of Proposition 2.6: First, suppose that the value of government costs $g$ is such that there exists a secession-proof allocation $(p, a)$. We shall demonstrate that for every value $g^{\prime}$, exceeding $g$, there is also a secession-proof allocation. Indeed, let $g^{\prime}>g$ and consider a new allocation $\left(p, a^{\prime}\right)$, where $a^{\prime}(t)=\left(g^{\prime} / g\right) a(t)$ for every $t$. Then $\int_{I} a^{\prime}(t) f(t) d t=g^{\prime}$ and since

$$
\int_{S}(|t-p|+a(t)) f(t) d t \leq g+D(S)
$$

for every region $S \subset N$, we have

$$
0 \leq \int_{S}|t-p| f(t) d t-D(S) \leq g-\int_{S} a(t) f(t) d t \leq g^{\prime}-\int_{S} a^{\prime}(t) f(t) d t
$$

or

$$
\int_{S}\left(|t-p|+a^{\prime}(t)\right) f(t) d t \leq g^{\prime}+D(S) .
$$

Thus, $\left(p, a^{\prime}\right)$ is a secession-proof allocation and there exists a level of government costs $g_{s}$ such that the cooperation is stable if and only if $g \geq g_{s}$. To complete the proof of the Lemma, it remains to show that $g_{s}$ is bounded. For this end, consider an allocation $(1 / 2, b)$ with $b(t)=g$ for all $t \in I$. It is secession-proof if and only if the inequality

$$
\int_{S} d\left(t, \frac{1}{2}\right) f(t) d t+\int_{S} b(t) f(t) d t \leq g+D(S)
$$

is satisfied for every region $S$. Consider an arbitrary region $S$. We have

$$
\int_{S} d\left(t, \frac{1}{2}\right) f(t) d t-D(S) \leq g\left(1-F_{S}\right)
$$


where $F_{S}=\int_{S} f(t) d t$. Moreover,

$$
\int_{S} d\left(t, \frac{1}{2}\right) f(t) d t-D(S)=\int_{S}\left(\left|t-\frac{1}{2}\right|-|t-m(S)|\right) f(t) d t \leq \int_{S}\left(\left|\frac{1}{2}-m(S)\right|\right) f(t) d t .
$$

Since $\bar{f}=\min _{t \in I} f(t)>0$,

$$
\left|\frac{1}{2}-m(S)\right| \leq \frac{1-F_{S}}{2 \bar{f}}
$$

Thus,

$$
\int_{S} d\left(t, \frac{1}{2}\right) f(t) d t-D(S) \leq \int_{I}\left(\left|\frac{1}{2}-m(S)\right|\right) f(t) d t \leq \frac{1-F_{S}}{2 \bar{f}}
$$

Then for every value $g \geq \frac{1}{2 f}$, the allocation $(1 / 2, b)$ is secession-proof and $g_{s}$ is, indeed, a finite number.

Proof of Proposition 2.7: Suppose that the value of government costs $g$ is such that cooperation is stable. Then there exists a secession-proof allocation $(p, a)$. Consider an arbitrary partition $\left(\mathrm{S}_{1}, \ldots, \mathrm{S}_{\mathrm{K}}\right)$. Since the inequality

$$
\int_{S_{k}}(|t-p|+a(t)) f(t) d t \leq D\left(S_{k}\right)+g
$$

holds for every $k=1, \ldots, K$, we have

$$
\int_{I}|t-p| f(t) d t+g=\sum_{k=1}^{K} \int_{S_{k}}(|t-p|+a(t)) f(t) d t \leq \sum_{k=1}^{K}\left(D\left(S_{k}\right)+g\right)
$$

That is, the cooperation is efficient.

Proof of Remark 3.1: Let $F$ be a log-concave distribution function. By the Implicit Functions Theorem, 


$$
l^{\prime}(t)=\frac{f(t)}{2 f(l(t))}
$$

Since $F$ is log-concave, we have

$$
\frac{f(l(t))}{F(l(t))}>\frac{f(t)}{F(t)}
$$

and therefore

$$
l^{\prime}(t)<\frac{F(t)}{2 F(l(t))}=1
$$

Proof of Lemma 3.3: Let $x \in X$ be a cost allocation such that a region $S$ is prone to secession. Assume, without loss of generality, that $m(S) \leq 1 / 2$. We shall carry out the proof of the lemma in four steps:

(i) $S \cup[0, m(S)]$ is prone to secession as well: It suffices to show that if there are $p$ and $q$ with $0 \leq p \leq q \leq m(S)$ and $S \cap[p, q]=\varnothing$, then $S^{1}=S \cup[p, q]$ is prone to secession. Indeed, by condition $(\alpha)$, we have

$\int_{S^{1}}\left(x(t)+d\left(t, \frac{1}{2}\right)\right) f(t) d t \geq \int_{p}^{q} d\left(t, \frac{1}{2}\right) f(t) d t+\int_{S}\left(x(t)+d\left(t, \frac{1}{2}\right)\right) f(t) d t>\int_{p}^{q} d\left(t, \frac{1}{2}\right) f(t) d t+g+D(S)$.

However,

$$
\int_{[p, q]} d\left(t, \frac{1}{2}\right) f(t) d t+D(S) \leq \int_{S^{1}}|t-m(S)| f(t) d t \geq D\left(S^{1}\right)
$$

and $\mathrm{S}^{1}$ is prone to secession.

(ii) Suppose that $S$ I $\left[m(S), \frac{1}{2}\right] \neq \varnothing$ and there are $p$ and $q$ with $m(S) \leq p<q<\frac{1}{2}$ and $S$ I $[p, q]=\varnothing$. Let $\hat{t} \in\left[m(S), \frac{1}{2}\right]$ be such that 


$$
F(t)-F(,(S))=\int_{S I}\left[m(S), \frac{1}{2}\right] f(t) d t
$$

Then $S^{2} \backslash\left[m(S), \frac{1}{2}\right] \mathrm{I}[m(S), t]$ is prone to secession: Since the shift from $S$ to $S^{2}$ is a measurepreserving transformation, it follows that $\mathrm{m}(S)=m\left(S^{2}\right)$ and, therefore, $D\left(S^{2}\right) \leq D(S)$. Moreover, condition $(\delta)$ implies that the difference

$$
\begin{gathered}
\int_{S^{2}}\left(x(t)+d\left(t, \frac{1}{2}\right)\right) f(t) d t-\int_{S}\left(x(t)+d\left(t, \frac{1}{2}\right)\right) f(t) d t= \\
\int_{S^{2} \backslash S}\left(x(t)+d\left(t, \frac{1}{2}\right)\right) f(t) d t-\int_{S \backslash S^{2}}\left(x(t)+d\left(t, \frac{1}{2}\right)\right) f(t) d t>0 .
\end{gathered}
$$

However, since

$$
\int_{S}\left(x(t)+d\left(t, \frac{1}{2}\right)\right) f(t) d t>D(S)+g
$$

it follows that

$$
\int_{S^{2}}\left(x(t)+d\left(t, \frac{1}{2}\right)\right) f(t) d t D\left(S^{2}\right)+g
$$

Thus, $S^{2}$ is prone to secession.

(iii) Suppose that $S \mathrm{I}\left[\frac{1}{2}, 1\right] \neq \varnothing$ and there are $p$ and $q$ with $\frac{1}{2} \leq p<q<1$ and

$S$ I $[p, q]=\varnothing$. Let $\bar{t} \in\left[\frac{1}{2}, 1\right]$ be such that

$$
F(t)-\frac{1}{2}=\int_{S \mathrm{I}\left[\frac{1}{2}, 1\right]} f(t) d t
$$


Then, $S^{3}=S \mathrm{I}\left[0, \frac{1}{2}\right] \mathrm{Y}\left[\frac{1}{2}, t\right]$ is prone to secession. As in the previous case, the shift from $S$ to

$S^{3}$ is a measure-preserving transformation. Thus, $m\left(S^{3}\right)=m(S)$. Moreover,

$$
D(S)-D\left(S^{3}\right)=\int_{S \backslash S^{3}}(t-m(S)) f(t) d t-\int_{S^{3} \backslash S} t-m(S) f(t) d t=\int_{S \backslash S^{3}} t f(t) d t-\int_{S^{3} \backslash S} t f(t) d t .
$$

Consider now the difference

$$
\int_{S \backslash S^{3}}\left(x(t)+d\left(t, \frac{1}{2}\right)\right) f(t) d t-\int_{S^{3} \backslash S}\left(x(t)+d\left(t, \frac{1}{2}\right)\right) f(t) d t
$$

It can be presented as

$$
\int_{S \backslash S^{3}} t f(t) d t-\int_{S^{3} \backslash S} t f(t) d t+\int_{S \backslash S^{3}} x(t) f(t) d t-\int_{S^{3 ! S}} x(t) f(t) d t
$$

The property $(\gamma)$ yields

$$
D(S)-D\left(S^{3}\right)<\int_{S}\left(x(t)+d\left(t, \frac{1}{2}\right)\right) f(t) d t-\int_{S^{3}}\left(x(t)+d\left(t, \frac{1}{2}\right)\right) f(t) d t
$$

Finally, the inequality

$$
\int_{S}\left(x(t)+d\left(t, \frac{1}{2}\right)\right) f(t) d t>D(S)+g
$$

implies that

$$
\int_{S}\left(x(t)+d\left(t, \frac{1}{2}\right)\right) f(t) d t>D\left(S^{3}\right)+g
$$

and $S^{3}$ is prone to secession. 
(iv) Suppose that there is $q>\frac{1}{2}$ such that $\left[\frac{1}{2}, q\right] \subset S$ and $S$ I $\left[1-q, \frac{1}{2}\right]=\varnothing$. Then $S^{4}=S \backslash\left[\frac{1}{2}, q\right] \mathrm{Y}\left[1-q, \frac{1}{2}\right]$ is prone to secession: Since $D\left(S^{4}\right) \leq D(S)$, the symmetry property $(\beta)$ implies that the region $S^{4}$ is prone to secession.

It is easy to verify that the proof of the Lemma follows from (i) - (iv).

Proof of the Main Result: It suffices to demonstrate that if $g \geq g_{e}$ the allocation $x_{g}$ is secession-proof. It is useful to recall that $g \geq g_{e}$, implies that (1) holds.

Recall that Lemma 3.3 yields that for any secession-proof allocation $x \in X$, the following two conditions should be satisfied for all $t \in[0,1]$ :

$$
\begin{aligned}
& \int_{L_{t}}\left(x(t)+d\left(t, \frac{1}{2}\right)\right) f(t) d t \leq g+D\left(L_{t}\right), \\
& \int_{R_{t}}\left(x(t)+d\left(t, \frac{1}{2}\right)\right) f(t) d t \leq g+D\left(R_{t}\right) .
\end{aligned}
$$

Note that

$$
\begin{gathered}
\int_{R_{t}}\left(x(t)+d\left(t, \frac{1}{2}\right)\right) f(t) d t=\int_{I}\left(x(t)+d\left(t, \frac{1}{2}\right)\right) f(t) d t- \\
\int_{L_{t}}\left(x(t)+d\left(t, \frac{1}{2}\right)\right) f(t) d t=g+D(I)-\int_{L_{t}}\left(x(t)+d\left(t, \frac{1}{2}\right)\right) f(t) d t .
\end{gathered}
$$

Thus, the necessary and sufficient condition for a cost allocation $x \in X$ to be secession-proof is that the inequality

$$
D(I)-D\left(R_{t}\right) \leq \int_{L t} x\left(x(t)+d\left(t, \frac{1}{2}\right)\right) f(t) d t \leq g+D\left(L_{t}\right)
$$


holds for all $t \leq \frac{1}{2}$. This inequality is equivalent to (3), given in Section 3:

$$
D(I)-\left(R_{t}\right)-H(t) \leq \int_{0}^{t} x(t) f(t) d t \leq g+D\left(L_{t}\right)-H(T) .
$$

To proceed, we need the following Lemma:

Lemma A.1: For every $t \leq \frac{1}{2}$, we have the following two equations:

$$
\begin{aligned}
& -\left(D\left(R_{t}\right)+H(t)\right)^{\prime}=\left(r(t)-\frac{1}{2}\right) f(t) \\
& \left(D\left(L_{t}\right)-H(t)\right)^{\prime}=\left(2 t-\frac{1}{2}-l(t) f(t)\right)
\end{aligned}
$$

Proof of Lemma A.1: Note that

$$
-\left(D\left(R_{t}\right)+H(t)\right)=\int_{t}^{r^{t}} s f(s) d t-\int_{r(t)}^{1} s f(s) d s-\int_{0}^{t} d\left(s, \frac{1}{2}\right) f(s) d s,
$$

and

$$
-\left(D\left(R_{t}\right)-H(t)\right)^{\prime}=-t f(t)+2 r^{\prime}(t) r(t) f(r(t))-\left(\frac{1}{2}-t\right) f(t) .
$$

But since

$$
r^{\prime}(t)=\frac{f(t)}{2 f(r(t)}
$$

it follows that, indeed,

$$
-\left(D\left(R_{t}\right)+H(t)\right)^{\prime}=\left(r(t)-\frac{1}{2}\right) f(t) .
$$

Similarly, 


$$
D\left(L_{t}\right)-H(t)=-\int_{0}^{l(t)} s f(s) d t+\int_{l(t)}^{t} s f(s) d s-\int_{0}^{t} d\left(s, \frac{1}{2}\right) f(s) d s
$$

and

$$
\left(D\left(L_{t}\right)-H(t)\right)^{\prime}=-2 l^{\prime}(t) l(t) f(l(t))+t f(t)-\left(\frac{1}{2}-t\right) f(t)
$$

Again since

$$
l^{\prime}(t)=\frac{f(t)}{2 f(l(t))}
$$

it follows that

$$
\left(D\left(L_{t}\right)-H(t)\right)^{\prime}=\left(2 t-\frac{1}{2}-l(t)\right) f(t)
$$

Denote $a(t)=r(t)-\frac{1}{2}$ for all $t \leq \frac{1}{2}$ and let us show that $a(\cdot)$ satisfies (3). Equation (5) implies that

$$
\int_{0}^{t} a(t) f(t) d t=D(I)-D\left(R_{t}\right)-H(t)
$$

and (1) yields

$$
\int_{0}^{t} a(t) f(t) d t \leq g+D\left(L_{t}\right)-H(t)
$$

Note that the assumption of gradually escalating median implies that the function a would be a solution of our problem if it were to satisfy the budget constraint. However, the value of $2 \int_{0}^{\frac{1}{2}} a(t) f(t) d t$ is not necessarily sufficient to cover the government costs $g$. Let us, therefore, modify the function a by adding to each individual a fixed payment $\lambda$ such that $\int_{0}^{\frac{1}{2}}(a(t)+\lambda) f(t) d t=\frac{g}{2}$, or,

$$
\lambda=g-2 \int_{0}^{\frac{1}{2}}\left(r(t)-\frac{1}{2}\right) f(t) d t
$$

We shall show that inequality (3) would not be violated by the function $x_{g}(t)=a(t)+\lambda$, i.e., 


\section{Lemma A.2:}

$$
D(I)-D\left(R_{t}\right)-H(t) \leq \int_{0}^{t} x_{g}(t) f(t) d t \leq g+D\left(L_{t}\right)-H(t)
$$

Proof of Lemma A.2: Recall that the left side of (3) was actually an equality for $a$. To show that it would still hold for $x_{g}(t)$, one has to demonstrate that $\lambda \geq 0$. By (4),

$$
\lambda=g-2 \int_{0}^{\frac{1}{2}}\left(r(t)-\frac{1}{2}\right) f(t) d t=g-2 D(I)+2 D\left(L_{\frac{1}{2}}\right)+2 H\left(\frac{1}{2}\right)
$$

Since $2 H\left(\frac{1}{2}\right)=D(I)$ and $D\left(L_{\frac{1}{2}}\right)=D\left(R_{\frac{1}{2}}\right)$, we have, by (1),

$$
\lambda=g-D(I)+\left(L_{\frac{1}{2}}\right)+D\left(R_{\frac{1}{2}}\right) \geq 0
$$

Before turning to the right side of (3), consider the expression

$$
g-H(t)+D\left(L_{t}\right)-\int_{0}^{t} x^{g}(t) f(t) d t
$$

Its derivative is $2 t-r(t)-l(t)$, which, by the assumption of gradually escalating median, is increasing in $t$. But, $1-r\left(\frac{1}{2}\right)-l\left(\frac{1}{2}\right)=0$, yielding $2 t-r(t)-l(t)<0$ for $t<\frac{1}{2}$. That is, the expression $c-H(t)+D\left(L_{t}\right)-\int_{0}^{t} x(t) f(t) d t$ is decreasing on the interval $\left[0, \frac{1}{2}\right]$. Thus, to complete the proof of the Lemma, it remains to verify that the right side of (3) holds for $t=\frac{1}{2}$ or

$$
\frac{g}{2} \leq g-H\left(\frac{1}{2}\right)+D\left(L_{\frac{1}{2}}\right)
$$

However, the last inequality is equivalent to

$$
g \geq 2 H\left(\frac{1}{2}\right)-2 D\left(L_{\frac{1}{2}}\right)=D(I)-D\left(L_{\frac{1}{2}}\right)-D\left(R_{\frac{1}{2}}\right)
$$


which is guaranteed by (1). This completes the proof of the main result.

Proof of Proposition 4.1: For $t \leq \frac{1}{2}$, we have

$$
D\left(L_{t}\right)=\frac{t^{2}}{4}, D\left(R_{t}\right)=\frac{(1-t)^{2}}{4}, D(I)=\frac{1}{4}, H(t)=\frac{t-t^{2}}{2} .
$$

First note that the cooperation is astable if the inequality (1) holds for all $L_{t}$ and $R_{t}$, i.e.,

$$
g \geq \frac{t}{2}-\frac{t^{2}}{4}
$$

Since the maximum of the right-hand side is $\frac{1}{8}$, it follows that $g_{s}=\frac{1}{8}$, i.e., the cooperation is stable and efficient if $g \geq \frac{1}{8} \cdot{ }^{18}$

Proof of Proposition 4.2: Consider the right side of (3) for the no-compensation allocation NC, which can be rewritten as

$$
\operatorname{tg} \leq \frac{3 t^{2}-2 t}{4}+g
$$

Then, for all $t \leq \frac{1}{2}$

$$
g \geq \phi(t) \equiv \frac{2 t-3 t^{2}}{4(1-t)}
$$

It is easy to see that $\varnothing(\cdot)$ is concave and its maximum given by a solution of the equation $3 t^{2}-6 t+2=0$ whose root is $t^{*}=1-\frac{1}{\sqrt{3}}=.423$. Thus, $g \geq \varnothing\left(t^{*}\right)=1-\frac{\sqrt{3}}{2}=.134>g_{s}$. That is,

\footnotetext{
${ }^{18}$ It is easy to verify that a further partitioning of the interval $[0, t]$ into smaller intervals would impact the efficiency bound, and it suffices to check the partitions with two sets only.
} 
for the range of government costs $g$, satisfying $.125<g<.134$, the inequality (4) is violated. Thus, the allocation $N C$ is not secession-proof as for this range of values of $g$, there are regions $L_{t}$, in particular for $t=.423$, that are prone to secession.

Proof of Proposition 4.4: It is easy to see that a linear allocation $x^{a}$ is determined by $x^{\alpha}(t)=\alpha t+g-\frac{\alpha}{4}$. The secession-proof conditions (4) for this allocation are:

$$
\frac{t^{2}}{4} \leq \frac{\alpha t^{2}}{2}+g t-\frac{\alpha t}{4} \leq \frac{3 t^{2}-2 t+4 g}{4}
$$

for all $t \in\left[0, \frac{1}{2}\right]$. Note that the left-hand side of the inequality implies

$$
\frac{t}{4} \leq \frac{\alpha t}{2}+g-\frac{\alpha}{4}
$$

which always holds for $g \geq \frac{1}{8}$ and $\alpha \leq 4 g$. It remains to consider only the right-hand side of the inequality (4). In other words, the rate $\alpha$ is secession-proof if and only if:

$$
\frac{\alpha t^{2}}{2}+g t-\frac{\alpha t}{4} \leq \frac{3 t^{2}-2 t+4 g}{4}
$$

or equivalently,

$$
\left(\frac{\alpha}{2}-\frac{3}{4}\right) t^{2}+\left(g-\frac{\alpha}{4}+\frac{1}{2}\right) t-g \leq 0
$$

for all $t \in\left[0, \frac{1}{2}\right]$. Since $\alpha \leq 1$, the left-hand side of the above inequality is a concave function whose maximal value is

$$
\frac{(4 g-\alpha+2)^{2}}{16(3-2 \alpha)}-g
$$

obtained at 


$$
\widetilde{t}=\frac{4 g-\alpha+2}{2(3-2 \alpha)}
$$

Two cases should be considered:

Case 1: $\tilde{t} \leq \frac{1}{2}$. This occurs when $4 g+\alpha \leq 1$. Note that since $g \geq \frac{1}{8}$, it also implies that $\alpha \leq 4 g$.

Simple algebra shows that

$$
\frac{(4 g-\alpha+2)^{2}}{16(3-2 \alpha)}-g \leq 0
$$

or

$$
\alpha^{2}+\alpha(24 g-4)+\left(4+16 g^{2}-32 g\right) \leq 0
$$

The last inequality holds if and only if

$$
\psi_{1}(g) \leq \alpha \leq \psi_{2}(g)
$$

where

$$
\begin{aligned}
& \psi_{1}(g)=2-12 g-\sqrt{128 g^{2}-16 g}, \\
& \psi_{2}(g)=2-12 g+\sqrt{128 g^{2}-16 g} .
\end{aligned}
$$

Since $g \geq \frac{1}{8}$, it is easy to verify that $\psi_{1}(g) \leq 1-4 g \leq \psi_{2}(g)$.

Therefore, in Case (1), the range of secession-proof values of $\alpha$ is the interval $\left[\max \left(0, \psi_{1}(g)\right), \max (0,1-\right.$ $4 g)]$

Case 2: $\tilde{t} \geq \frac{1}{2}$. This occurs when $4 g+\alpha \geq 1$. Note that the function $\left(\frac{\alpha}{2}-\frac{3}{4}\right) t^{2}+\left(g-\frac{\alpha}{4}+\frac{1}{2}\right) t-g$ is increasing on the interval $\left(0, \frac{1}{2}\right)$ and its value at $t=\frac{1}{2}$ is $-\frac{1}{16}-\frac{5_{g}}{8}$, which is always negative. 
Therefore, the only upper bounds for $\alpha$ are 1 and $4 g$. Thus, in Case 2, the range of secession-proof values of $\alpha$ is the interval $[\max (0,1-g), \min (4 g, 1)]$.

It is easy to see that the function $\psi_{1}$ decreases and $\psi_{1}(g)=0$ at $g=1-\frac{\sqrt{3}}{2}$.

If $\frac{1}{8} \leq g \leq 1 \frac{\sqrt{3}}{2}$, the range of secession-proof values of $\alpha$ is the union of the two intervals,

$\left[\psi_{1}(g), 1-4 g\right]$ (generated by Case 1) and [1 - 4g, 4g] (generated by Case 2). Thus, we obtain the interval $\left[\psi_{1}(g), 4 g\right]$.

If $1 \frac{\sqrt{3}}{2} \leq g \leq \frac{1}{4}$, the range of secession-proof values of $\alpha$ is the union of the two intervals, $[0,1-4 g]$ (generated by Case 1 ) and $[1-4 g, 4 g]$ (generated by Case 2). Thus, we obtain the interval $[0,4 g]$. If $g \geq \frac{1}{4}$, only Case 2 can occur and the range of secession-proof values of $\alpha$ is the interval $[0,1]$.

That is, the allocation $x^{\alpha}(t)$ is secession-proof if the equalization rate $\alpha$ satisfies:

$$
\left\{\begin{array}{ccc}
\psi_{1}(g) \leq \alpha \leq 4 g & \text { if } & g \in[0.125,0.14] \\
0 \leq \alpha \leq 4 g & \text { if } & g \in[0.14,0.25] \\
0 \leq \alpha \leq 1 & \text { if } & g \geq 0.25
\end{array}\right.
$$

Finally, by setting interval $\psi(g)=\max \left[\psi_{1}(g), 0\right]$, we complete the proof of the proposition

\section{References}

Ahmad, E., Li, K., Richardson, T. and R. Singh (2002) "Recentralization in China?", IMF Working Paper \#02 - 168. 
Alesina, A. and E. Spolaore (1996) "International Conict, Defense Spending and the Size of the Countries", NBER Working Paper, \# 5694.

Alesina, A. and E. Spolaore (1997) "On the Number and Size of Nations", Quarterly Journal of Economics 113, 1027-1056.

Alesina, A. and R. Wacziarg (1998) "Openness, Country Size and the Government", Journal of Public Economics 69, 305-322.

Alesina, A., Spolaore, E. and R. Wacziarg (2000) "Economic Integration and Political Disintegration", American Economic Review 90, 1276-1296.

Ahmad, E. and J. Craig (1997) "Intergovernmental Transfers" in Fiscal Federalism in Theory and Practice, International Monetary Fund, Washington DC.

Barro, R.J. (1991) "Small is Beautiful", The Wall Street Journal, October 11.

Barro, R.J. (1998) Getting it Right, The MIT Press, Cambridge.

Boadway, R.W. and P.A.R Hobson (1993) “Intergovernmental Fiscal Relations in Canada", Report of Canadian Tax Foundation, Toronto.

Bolton, P. and G. Roland (1996) "Distributional Conicts, Factor Mobility, and Political Integration", American Economic Review, Papers and Proceedings, 86, 99-104.

Bolton, P., Roland, G. and E. Spolaore (1996) "Economic Theories of the Breakup and Integration of Nations", European Economic Review 40, 697-706.

Bolton, P. and G. Roland (1997) “The Break-Up of Nations: A Political Economy Analysis", Quarterly Journal of Economics 113, 1057-1090.

Bordignon, M. and S. Brusco (2001) "Optimal Secession Rules", European Economic Review 45, $1811-1834$.

Buchanan, J.M. and R.I. Faith (1987) "Secessions and the Limits of Taxation: Toward a Theory of Internal Exit", American Economic Review 77, 1023-31.

Caplin, A. and B. Nalebu- (1991) "Aggregation and Social Choice: A Mean Voter Theorem", Econometrica 59, 1-24. 
Casella, A. (1992) "On Markets and Clubs: Economic and Political Integration of Regions with Unequal Productivity", American Economic Review, Papers and Proceedings 82, 115-121.

Casella, A. and J. Feinstein (2002) "Public Goods in Trade: On the Formation of Markets and Political Jurisdictions", International Economic Review, forthcoming.

Clark, D.H. (1997) "The Fiscal Transfer System in Canada", in Financing Decentralized Expenditures: An International Comparison of Grants, E. Ahmad, ed., Edward Edgar, Cheltenham, England.

Craig, J. (1997) "Australia", in Fiscal Federalism in Theory and Practice, International Monetary Fund, Washington, DC.

Cremer, H., De Kerchove, A.M. and J. Thisse (1985) "An Economic Theory of Public Facilities in Space", Mathematical Social Sciences 9, 249-262.

Dabla-Norris, E., Martinez-Vasquez, J. and J. Norregaard (2000), Fiscal Decentralization and Macroeconomic Performance: The Case of Russia, Ukraine, and Kazakhstan, IMF, Washington DC, forthcoming.

Dabla-Norris, E. and S. Weber (2001), "Regional Disparities and Transfer Policies in Russia: Theory and Evidence", in Institutional Change in Transition Economies, M. Cuddy and R.Gekker, eds., Ashgate Publishing Ltd., UK.

Drèze, J. (1993) "Regions of Europe", Economic Policy 17, 265-307.

Economist "Little Countries: Small but Perfectly Formed", January 3, 1998.

Easterly, W. and S. Rebello (1993) "Fiscal Policy and Economic Growth: An Empirical Investigation", Journal of Monetary Economics 32, 417-458.

Feinstein, J. (1992) "Public Good Provision and Political Stability in Europe", American Economic Review, Papers and Proceedings 82, 323-329.

Fidrmuc, J. (1999) "Stochastic Shocks and Incentives for (Dis)Integration", CEPRWorking paper \#2104.

Friedman, D. (1977) "A Theory of the Size and Shape of Nations", Journal of Political Economy, 85, 59-77. 
Greenberg, J. and S. Weber (1986) "Strong Tiebout Equilibrium Under Restricted Preferences Domain", Journal of Economic Theory 38, 101-117.

Guesnerie, R. and C. Oddou (1981) "Second Best Taxation as a Game", Journal of Economic Theory 25, 67-91.

Guesnerie, R. and C. Oddou (1987) "Increasing Returns to Size and their Limits", Scandinavian Journal of Economics, 90, 259-273.

Haimanko, O., Le Breton, M. and S. Weber (2000) "Transfers in a Polarized Country: Bridging the Gap between Efficiency and Stability", CORE Discussion paper 2002/18.

Hardy, G.H., Littlewood, J.E. and G. Polya (1934) Inequalities, Cambridge University Press, London. Hayo, B. and M. Wrede (2002) "Fiscal Equalization: Principles and an Application to the European Union", mimeo.

Hu, C. and C. Tan (1996) "Empirical Study on the Regional Economic Disparities in China", DRC Report \#42, State Council Research Development Center, Beijing.

Hu, D. and M. Fujita (2001) "Regional Disparity in China 1985-1994: The Effects of Globalization and Economic Liberation", Annals of Regional Science, 35 (3), 3-37.

Jéhiel, P. and S. Scotchmer (2001) "Constitutional Rules of Exclusion in Jurisdiction Formation", Review of Economic Studies 68, 393-411.

Krelove, R., Stotsky, J.G., and C.L. Vehorn (1997) "Canada", in Fiscal Federalism in Theory and Practice, International Monetary Fund, Washington, DC.

Mauro, P. (1995) “Corruption and Growth", Quarterly Journal of Economics 110, 681- 712.

Moreno, L. (2001) "Divided Societies, Electoral Polarization and the Basque Country" Unidad de Politicas Comparadas, CSIC, Working Paper 01-07.

Olofsgard, A. (1999) "Secessions and Nationalism in a Model with Size Externalities and Imperfect Mobility", Mimeo, Institute for International Economic Studies.

People's Daily "China Facts and Figures on Tibet in 1999", February 8, 2000.

Perroni, C. and K. Scharf (2001) "Tiebout with Politics: Capital Tax Competition and Constitutional Choices", Review of Economic Studies 68, 133-154. 
Persson, T. and G. Tabellini (1996a) "Federal Fiscal Constitutions: Risk Sharing and Moral Hazard", Econometrica 64, 623-646.

Persson, T. and G. Tabellini (1996b) "Federal Fiscal Constitutions: Risk Sharing and Redistribution", Journal of Political Economy 104, 979-1009.

Persson, T. and G. Tabellini (1999) "Political Economics and Public Finance", Mimeo, Bocconi University.

Spahn, P.B. and W. F ottinger (1997) "Germany", in Fiscal Federalism in Theory and Practice, International Monetary Fund, Washington, DC.

Ter-Minassian, T. (1997) "Intergovernmental Fiscal Relations in a Macroeconomic Perspective: An Overview", in Fiscal Federalism in Theory and Practice, International Monetary Fund, Washington, DC.

Triesman D. (1996) "The Politics of Intergovernmental Transfers in Post-Soviet Russia", British Journal of Political Science, 26, 299-335.

Triesman D. (1998) "Deciphering Russia's Federal Finance: Fiscal Appeasement in 1995 and 1996", Europe-Asia Studies 50, 893-906.

Weber, S. (1992) "On Hierarchical Spatial Competition", Review of Economic Studies 59, 407-425.

Weber, S. and S. Zamir (1985) "Proportional Taxation: Nonexistence of Stable Structures in an Economy with Public Good", Journal of Economic Theory 35, 178-185.

Wei, S.J. (1991) "To Divide or to Unite: A Theory of Secessions", Mimeo, University of California at Berkeley.

Wittman, D. (1991) "Nations and States: Mergers and Acquisitions, Dissolution and Divorce", American Economic Review, Papers and Proceedings 81, 126-129.

Wooders, M.H. (1978) "Equilibria, The Core, and Jurisdiction Structures in Economies with a Local Public Good", Journal of Economic Theory 18, 328-348.

Young, R. (1998) "Secession Games" in Palgrave Dictionary of Economics and the Law, P. Newman, eds., Stockton Press, New York. 


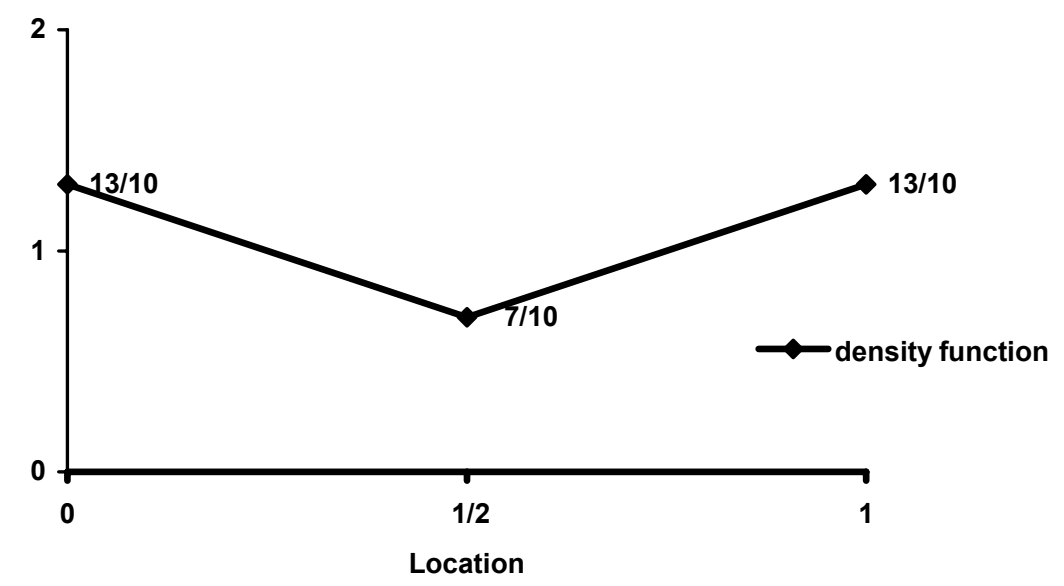

Figure 1: Bimodal Distribution that satisfies GEM 


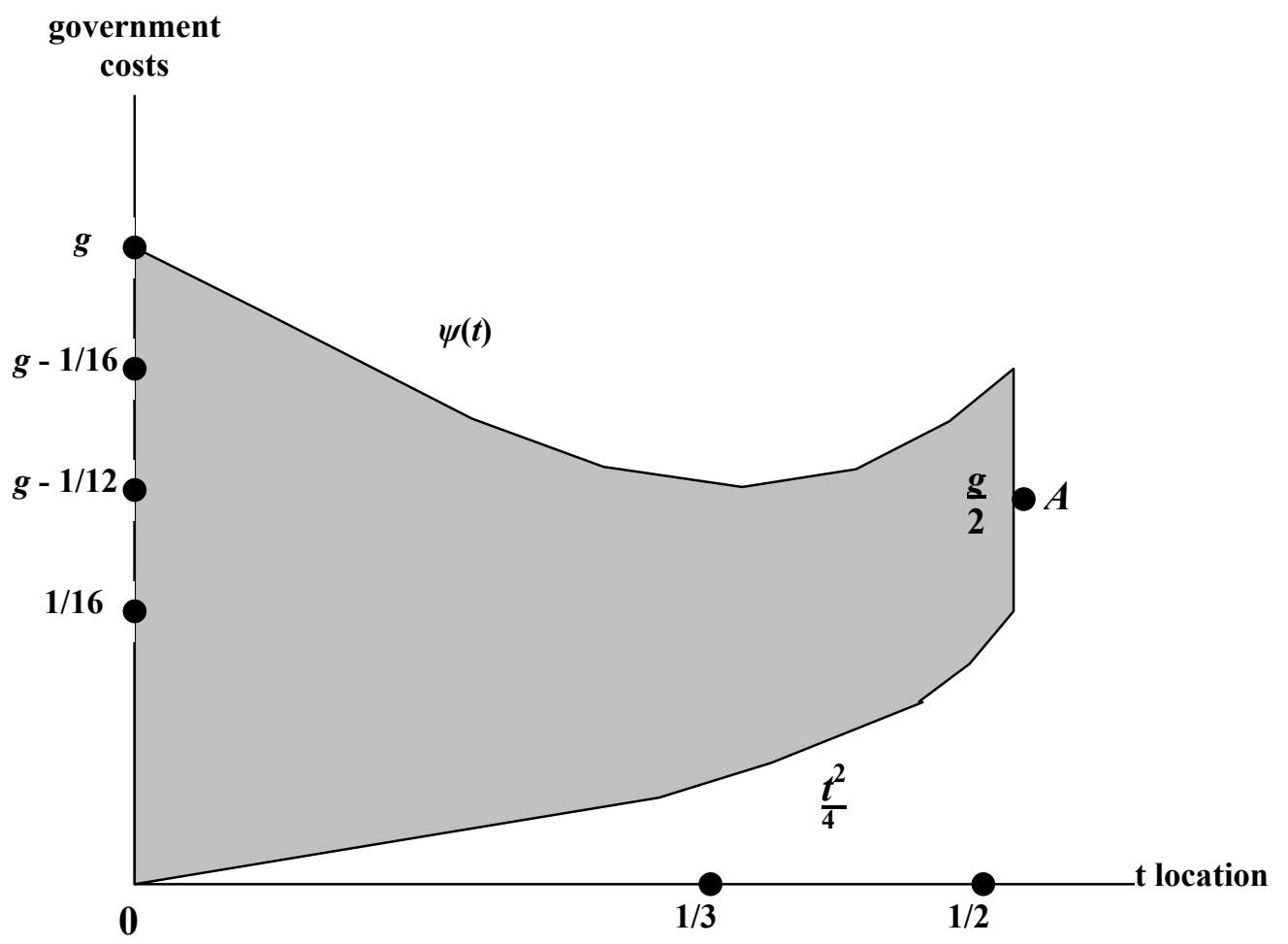

Figure 2: The Secession-Proof Area 


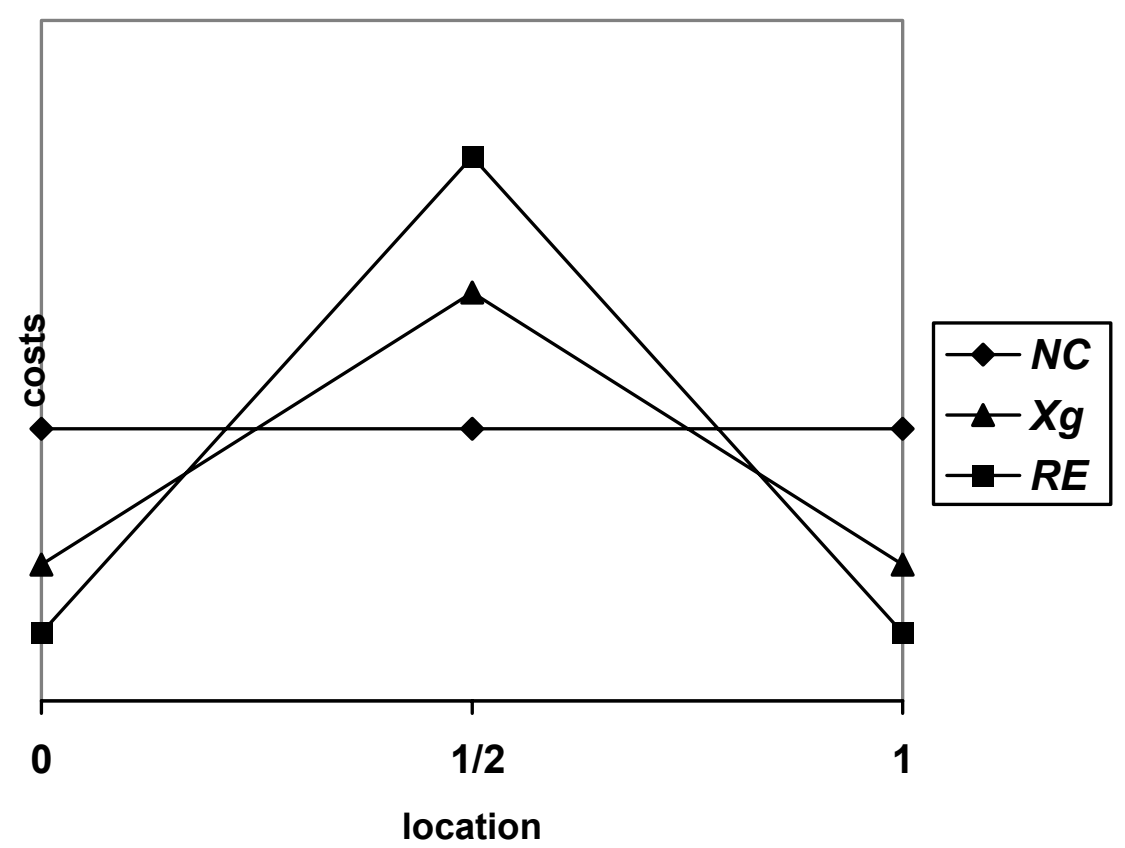

Figure 3: Graphs of No-Copensation Allocation ( $N C$,

Egalitarian Rawlsian Allocation ( $R E)$, and Secession-Proof Allocation $\left(x_{g}\right)$ 


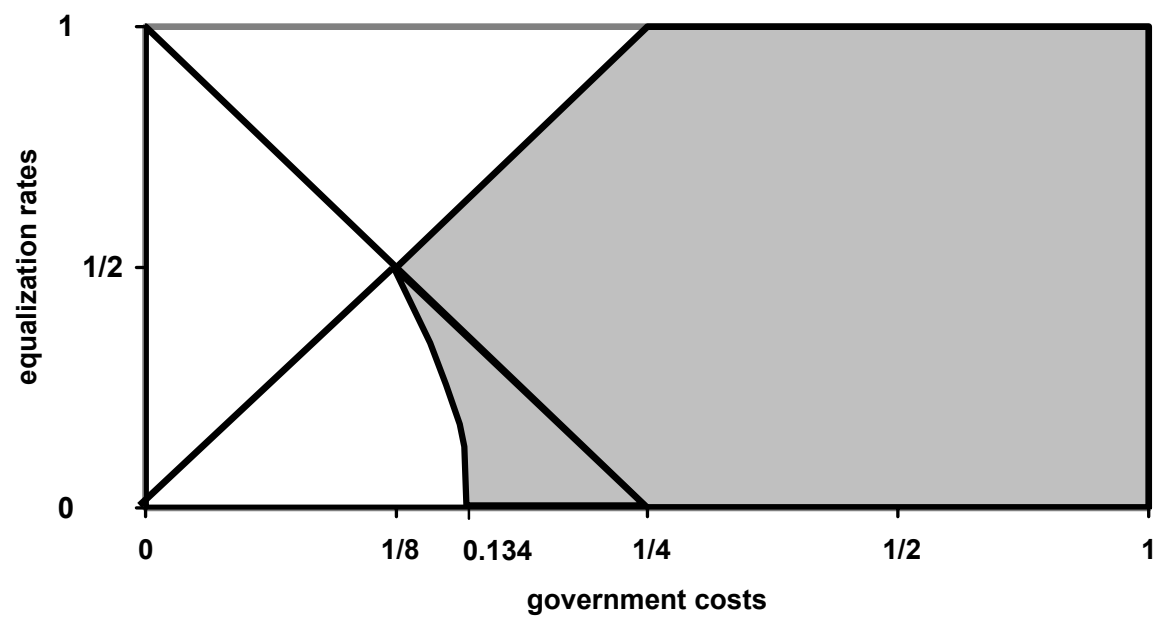

Figure 4: Secession-Proof Rates as g varies 


\begin{tabular}{|l|c|c|c|c|}
\hline \multicolumn{1}{|c|}{ Provinces } & $\begin{array}{c}\text { Notional } \\
\text { revenue yield }\end{array}$ & Equalization & $\begin{array}{c}\text { Index of } \\
\text { Tax } \\
\text { capacity }^{\mathrm{b}}\end{array}$ & $\begin{array}{c}\text { Index of } \\
\text { fiscal } \\
\text { capacity }^{\mathrm{c}}\end{array}$ \\
\hline Newfoundland & 2,898 & 1,686 & 0.63 & 0.93 \\
Prince Edward & 2,988 & 1,595 & 0.65 & 0.93 \\
Island & 3,517 & 1,066 & 0.76 & 0.93 \\
Nova Scotia & 3,295 & 1,288 & 0.71 & 0.93 \\
New Brunswick & 3,973 & 610 & 0.86 & 0.93 \\
Quebec & 5,085 & $\ldots$ & 1.10 & 1.03 \\
Ontario & 3,737 & 847 & 0.81 & 0.93 \\
Manitoba & 4,058 & 525 & 0.88 & 0.93 \\
Saskatchewan & 6,306 & $\ldots$ & 1.36 & 1.28 \\
Alberta & 4,808 & $\ldots$ & 1.04 & 0.97 \\
British Columbia & & & & \\
\hline
\end{tabular}

a/ Per capita yield of tax bases at national average tax rates.

$\mathrm{b} /$ Notional revenue before equalization relative to the national average.

c/ Notional revenue yield after equalization relative to the national average.

Source: Broadway and Hubson (1993), p.59.

Table 1: Provincial Per Capita Notional Revenues Before and After Equalization, 1990-91, in Canada 


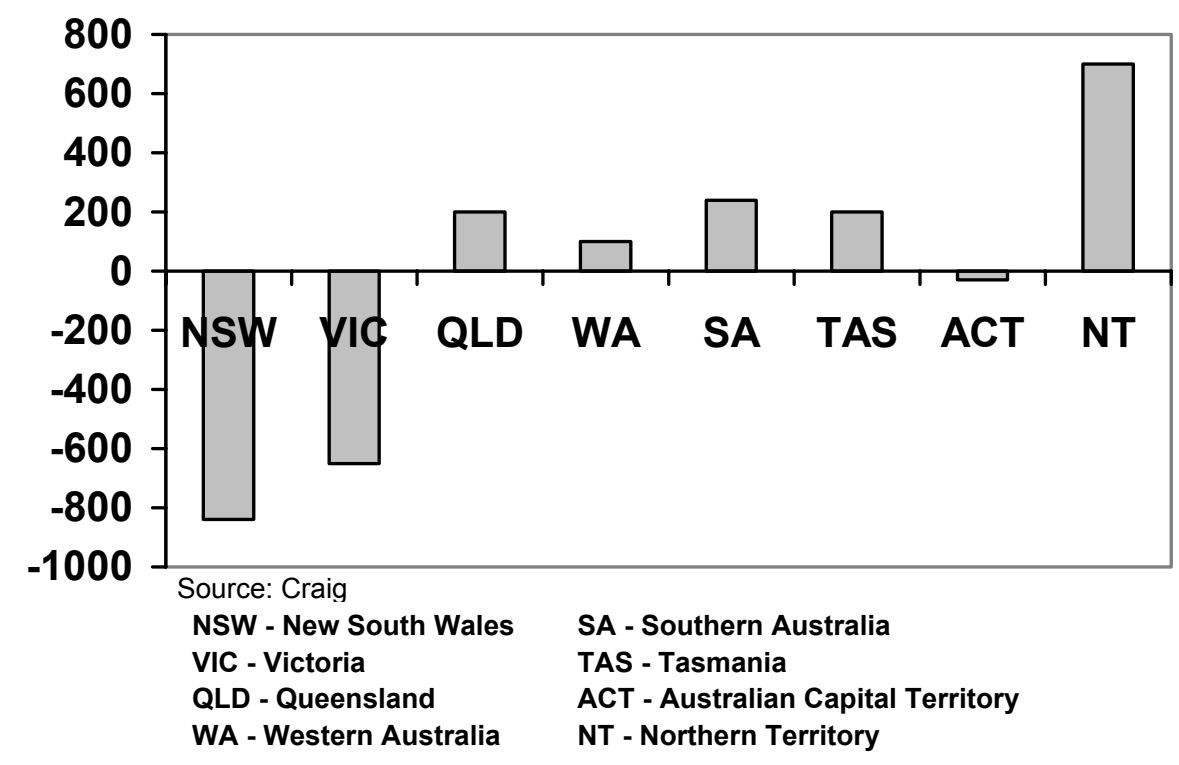

Table 2: Impact of Horizontal Equalization Grants Relative to Equal Per Capita Allocation, 1996/96 (in millions of Australian dollars) 


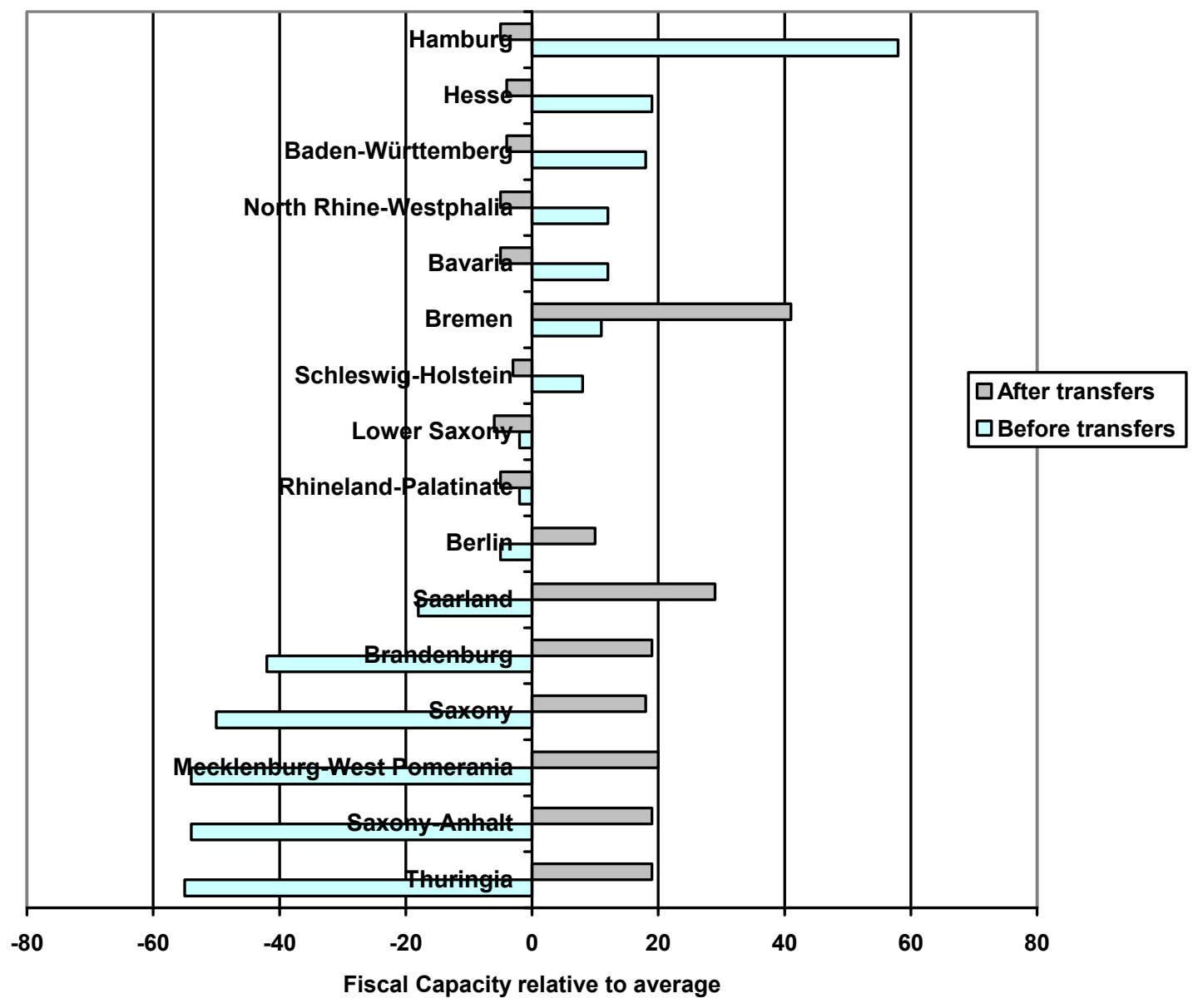

Table 3: Germany: Per Capita Fiscal Capacity of States

Before and After Equalization (in percent of average) 


\begin{tabular}{c|c|c|c|c}
\hline Year & Mean & Coefficient of Variation & Minimum & Maximum \\
\hline 1993 & 219.7 & 0.775 & 100.6 & 1198.2 \\
1994 & 959.7 & 1.191 & 359.8 & 8000.7 \\
1995 & 1904.9 & 1.023 & 720.2 & 13004.3 \\
1996 & 2835.7 & 1.067 & 1050.3 & 16521.1 \\
1997 & 3730.1 & 1.187 & 1336.7 & 30543.5 \\
1998 & 3184.4 & 1.022 & 1121.5 & 22559.8 \\
\hline
\end{tabular}

Source: Dabla-Norris, Martinez-Vasquez, and Norregaard (2002).

Table 4: easure of Horizontal Fiscal Imbalance in Russia:

Per Capita Regional Expenditures, 1993-1998 


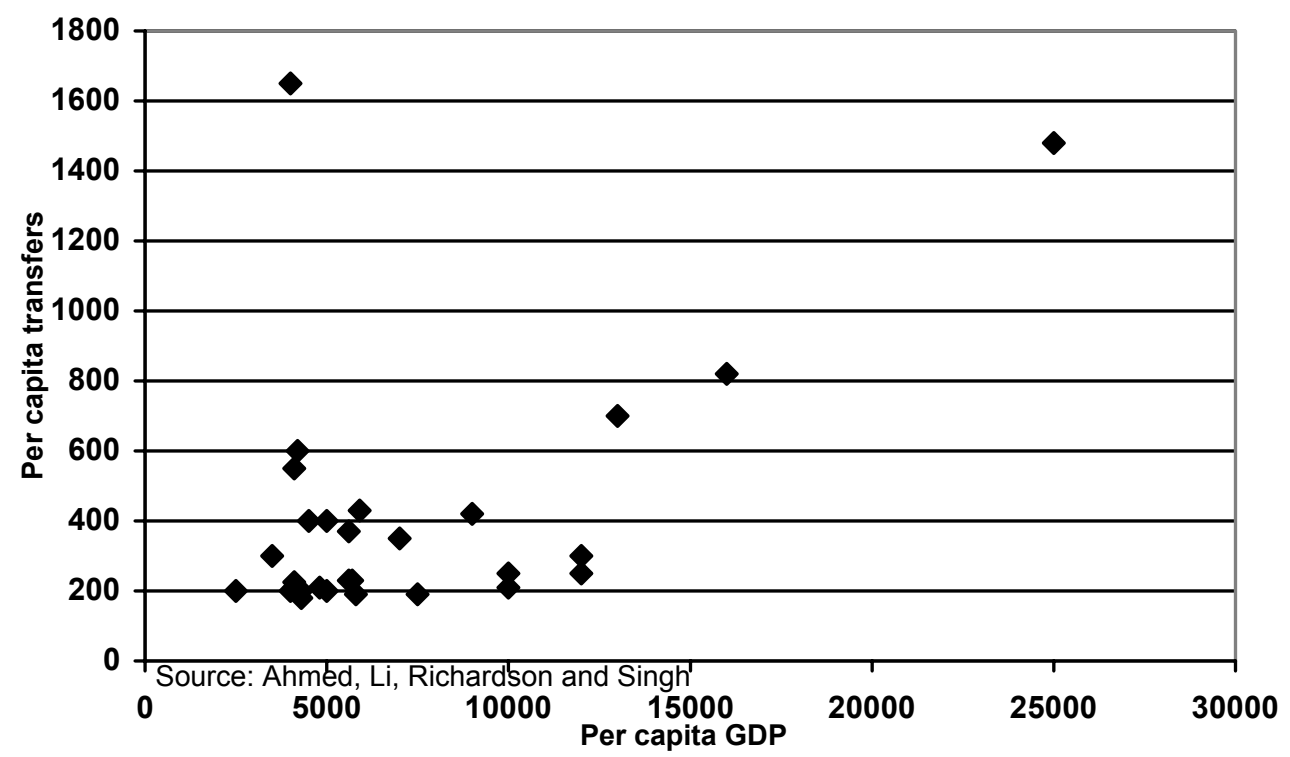

Table 5: Total Transfers Per Capita and GDP Per Capita in 1998, in China 